\title{
Pulsed Electric Fields to Improve the Use of Non-Saccharomyces Starters in Red Wines
}

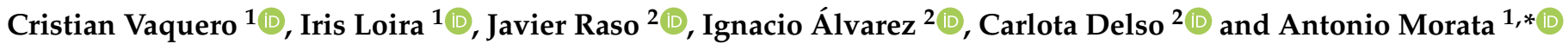 \\ 1 enotecUPM, Chemistry and Food Technology Department, ETSIAAB, Universidad Politécnica de Madrid, \\ Avenida Puerta de Hierro 2, 28040 Madrid, Spain; c.vaquero@upm.es (C.V.); iris.loira@upm.es (I.L.) \\ 2 Tecnología de los Alimentos, Facultad de Veterinaria, Instituto Agroalimentario de Aragón-IA2, Universidad \\ de Zaragoza-CITA, c/Miguel Servet, 177, 50013 Zaragoza, Spain; jraso@unizar.es (J.R.); \\ ialvalan@unizar.es (I.Á.); carlotad@posta.unizar.es (C.D.) \\ * Correspondence: antonio.morata@upm.es
}

Citation: Vaquero, C.; Loira, I.; Raso, J.; Álvarez, I.; Delso, C.; Morata, A. Pulsed Electric Fields to Improve the Use of Non-Saccharomyces Starters in Red Wines. Foods 2021, 10, 1472. https://doi.org/10.3390/ foods10071472

Academic Editor: Alice Vilela

Received: 21 May 2021

Accepted: 21 June 2021

Published: 25 June 2021

Publisher's Note: MDPI stays neutral with regard to jurisdictional claims in published maps and institutional affiliations.

Copyright: (c) 2021 by the authors. Licensee MDPI, Basel, Switzerland. This article is an open access article distributed under the terms and conditions of the Creative Commons Attribution (CC BY) license (https:// creativecommons.org/licenses/by/ $4.0 /)$
Abstract: New nonthermal technologies, including pulsed electric fields (PEF), open a new way to generate more natural foods while respecting their organoleptic qualities. PEF can reduce wild yeasts to improve the implantation of other yeasts and generate more desired metabolites. Two PEF treatments were applied; one with an intensity of $5 \mathrm{kV} / \mathrm{cm}$ was applied continuously to the must for further colour extraction, and a second treatment only to the must (without skins) after a 24-hour maceration of $17.5 \mathrm{kV} / \mathrm{cm}$ intensity, reducing its wild yeast load by up to $2 \log \mathrm{CFU} / \mathrm{mL}$, thus comparing the implantation and fermentation of inoculated non-Saccharomyces yeasts. In general, those treated with PEF preserved more total esters and formed more anthocyanins, including vitisin A, due to better implantation of the inoculated yeasts. It should be noted that the yeast Lachancea thermotolerans that had received PEF treatment produced four-fold more lactic acid $(3.62 \pm 0.84 \mathrm{~g} / \mathrm{L})$ than the control of the same yeast, and Hanseniaspora vineae with PEF produced almost three-fold more 2-phenylethyl acetate than the rest. On the other hand, 3-ethoxy-1-propanol was not observed at the end of the fermentation with a Torulaspora delbrueckii (Td) control but in the Td PEF, it was observed $(3.17 \pm 0.58 \mathrm{mg} / \mathrm{L})$.

Keywords: pulsed electric fields (PEF); colour extraction; vitisin A; Lachancea thermotolerans; lactic acid; Hanseniaspora vineae; 2-phenylethyl acetate; Torulaspora delbrueckii; 3-ethoxy-1-propanol

\section{Introduction}

Pulsed electric fields (PEF) are a nonthermal technique that causes electroporation of cell membranes by applying very short pulses ( $\mu s)$ of a high-intensity electric field $(\mathrm{kV} / \mathrm{cm})$. Irreversible electroporation leads to the formation of permanent conductive channels in the cytoplasmic membrane of the cells resulting in the loss of cell viability, leakage of cytoplasmic compounds and loss of cell turgor [1]. The food industry may take advantage of the effect produced by PEF in microbial cells and cells of animal and plant tissues to improve many different operations. The ability of PEF to inactivate vegetative cells of microorganisms, enhance mass transfer, and modify food structure may contribute to improving the competitiveness of the food industry by improving food quality, reducing energy inputs, and contributing to the bioeconomy strategy for sustainable growth [2].

Wineries can also benefit from PEF in improving several kinds of processes in winemaking. Several studies have demonstrated that electroporation of red grape skin cells before the maceration-fermentation step reduces the duration of maceration and/or improves a wine's colour and concentration of polyphenolic compounds without impairing its sensorial attributes [3-5]. On the other hand, PEF has been proposed as a technique to enhance wine quality by guaranteeing reproducible fermentations and reducing or replacing the use of $\mathrm{SO}_{2}$ for wine stabilisation due to the capability of PEF to inactivate microorganisms while preserving physicochemical and sensorial properties [3]. 
One of the most popular alcoholic beverages in the world [6], wine comes from grape fermentation and has a variety of microbiota on the grape skin that can deteriorate the wine, such as yeasts of the Dekkera/Brettanomyces genus and lactic acid bacteria [7,8]. It is controlled with $\mathrm{SO}_{2}$, which poses certain health risks [9] and worsens sensory analysis. With this new technology (PEF), it is possible to inactivate unwanted microbiota [10], increase the extraction of phenolic compounds and colour [11], and decrease the $\mathrm{SO}_{2}$ dosage [12]. Furthermore, PEF technology can generalise more stable fermentations with selected non-Saccharomyces yeasts that provide higher sensory quality such as Hanseniaspora vineae, Torulaspora delbrueckii, Lachancea thermotolerans, Schizosaccharomyces pombe and Metschnikowia pulcherrima [13-15]. The relevance of these non-Saccharomyces yeasts has increased in recent years [16]. One of the major problems that some of these yeasts pose with respect to Saccharomyces cerevisiae is their weak implantation in addition to their low/medium fermentation power, which makes them poor competitors and which yields a low population from the vineyard [17]. The objective of this work is to evaluate the fermentation effect of different non-Saccharomyces yeasts on oenological and sensory characteristics of red wine from Grenache grapes. To obtain this objective, crushed grape was first treated by PEF to obtain a must with a sufficient content of polyphenols after few hours of maceration. Secondly, after removing the grape must, the must was treated again by PEF to reduce the indigenous flora and facilitate the implantation of non-Saccharomyces yeasts.

\section{Materials and Methods}

\subsection{Grape Sample}

For this trial, one hundred kilograms of Vitis vinifera var. Grenache grapes were harvested manually in the Campo de Borja appellation, located in the Spanish region of Aragón, at the end of September 2020.

\subsection{PEF Processing \\ 2.2.1. PEF Unit}

A PEF generator EPULSUS PM1-10 (Energy Pulse Systems LDA, Lisbon, Portugal) was used for the application of PEF treatments. This generator, with an output voltage of $10 \mathrm{kV}$ and a maximum current intensity of $200 \mathrm{~A}$, provides monopolar rectangular pulses with a pulse duration between 1 and $200 \mu \mathrm{S}$ at a maximum frequency up to $200 \mathrm{~Hz}$. Voltage and electric current were measured using a digital oscilloscope (TDS 3021, Tektronix, Wilsonville, OR, USA).

\subsubsection{PEF Processing of Grapes}

Before PEF processing, grapes were de-stemmed and crushed (Figure 1) (Master E-10 destemmer, Enomundi, Zaragoza, Spain). Grape must (electrical conductivity $1.4 \pm 0.1 \mathrm{mS} / \mathrm{cm}$ ) was pumped by an eccentric screw pump through a co-linear treatment chamber. The co-linear treatment chamber, with an inner diameter of $20 \mathrm{~mm}$, consisted of three stainless steel electrodes with the central electrode connected to high voltage and the outer electrodes connected to the ground. This treatment chamber configuration defines two cylindrical treatment zones with a gap of $20 \mathrm{~mm}$ and a diameter of $20 \mathrm{~mm}$. As in a co-linear configuration, the electric field strength is not homogeneously distributed; the electric field strength used to characterise the PEF treatment corresponded to the field strength in the middle position of the central axis of the treatment zones. The flow rate $(120 \mathrm{~kg} / \mathrm{h})$ provided a residence time of the crushed grape in the treatment zone of $0.38 \mathrm{~s}$. A total treatment time of $1800 \mu \mathrm{S}$ ( 45 pulses of $40 \mu \mathrm{S}$ ) was applied at an electric field strength of $5 \mathrm{kV} / \mathrm{cm}$, corresponding to a total specific energy of $63.4 \mathrm{~kJ} / \mathrm{kg}$. The temperature of the crushed grape before the treatment was $17^{\circ} \mathrm{C}$, and after the treatments, the temperature was increased at $32 \pm 2{ }^{\circ} \mathrm{C}$. Just after processing, the temperature was rapidly decreased to $10^{\circ} \mathrm{C}$ using a cooling plate $\left(4{ }^{\circ} \mathrm{C}\right)$ and two lots of $30 \mathrm{~kg}$ were distributed in $50 \mathrm{~L}$ stainless steel tanks. The tanks were maintained in a cooling chamber $\left(5^{\circ} \mathrm{C}\right)$ for the duration of maceration $(24 \mathrm{~h})$ to prevent microbial growth. After $24 \mathrm{~h}$ of maceration, Granache must 
was obtained after pressing the crushed grape with a water press (Enomundi, Zaragoza, Spain) at a maximum pressure of 1 bar.

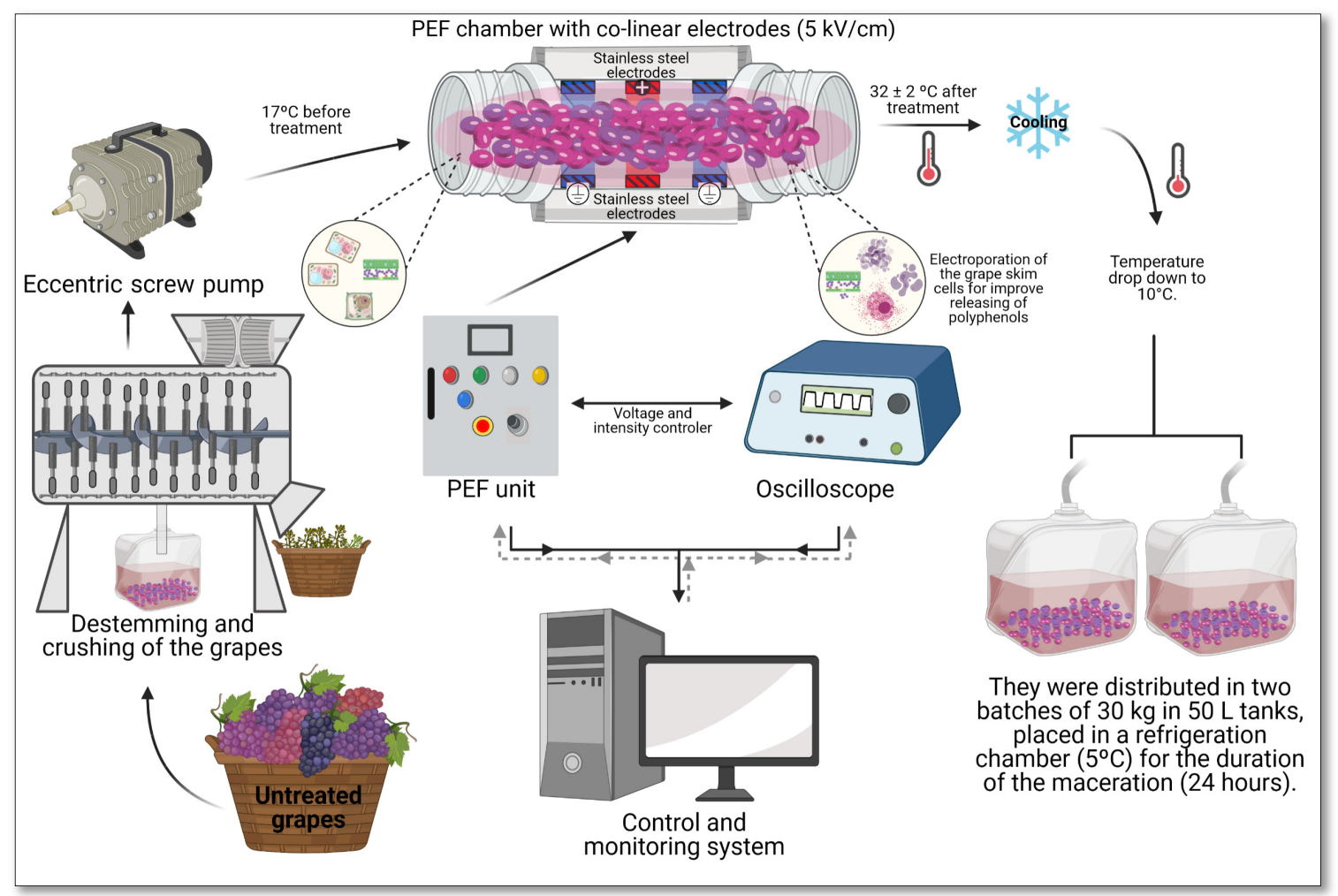

Figure 1. Schematic of pulsed electric fields PEF processing of grapes.

\subsubsection{PEF Processing of Must}

Grenache must obtained from grapes treated by PEF and macerated for $24 \mathrm{~h}$ at $5{ }^{\circ} \mathrm{C}$ (Figure 2) was decontaminated by a PEF treatment of higher intensity $(17.5 \mathrm{kV} / \mathrm{cm})$ to facilitate the implantation of non-Saccharomyces starters.

A pump (Ismatec, Glattbrugg, Switzerland) was used to pump the must from a reservoir through silicone tubes to a coiled stainless steel tube (Øin $5 \mathrm{~mm}$, Øout $5.5 \mathrm{~mm}, 230 \mathrm{~cm}$ length), which was immersed into a heating bath located before the treatment chamber. The treatment chamber consisted of two parallel stainless steel electrodes $(30 \mathrm{~mm} \times 5 \mathrm{~mm}$ ) with a gap of $4 \mathrm{~mm}$. After the treatment chamber, the temperature of the must was immediately decreased through a similar stainless steel tube immersed into a cooling bath at $4{ }^{\circ} \mathrm{C}$. Grape must (electrical conductivity $1.67 \pm 0.1 \mathrm{mS} / \mathrm{cm}$ ) was pumped through the treatment chamber with a throughput of $10 \mathrm{~L} / \mathrm{h}$, providing a residence time of the must in the treatment zone of $0.24 \mathrm{~s}$. A total treatment time of $225 \mu \mathrm{s}$ ( 45 pulses of $5 \mu \mathrm{s}$ ) was applied at an electric field strength of $17.5 \mathrm{kV} / \mathrm{cm}$, corresponding to a total specific energy of $115.0 \mathrm{~kJ} / \mathrm{kg}$. The temperature of the grape must before the treatment was $25^{\circ} \mathrm{C}$, and after the treatments, the temperature increased to $53 \pm 2{ }^{\circ} \mathrm{C}$. After PEF treatment, the temperature of the must decreased in a few seconds to below $15^{\circ} \mathrm{C}$ in the heat exchanger located after the treatment chamber. To evaluate the effect of PEF treatment in the extraction of polyphenols, untreated grapes were processed similarly to PEF-treated grapes but with the PEF generator switched off. All the treatments were conducted in duplicate. 


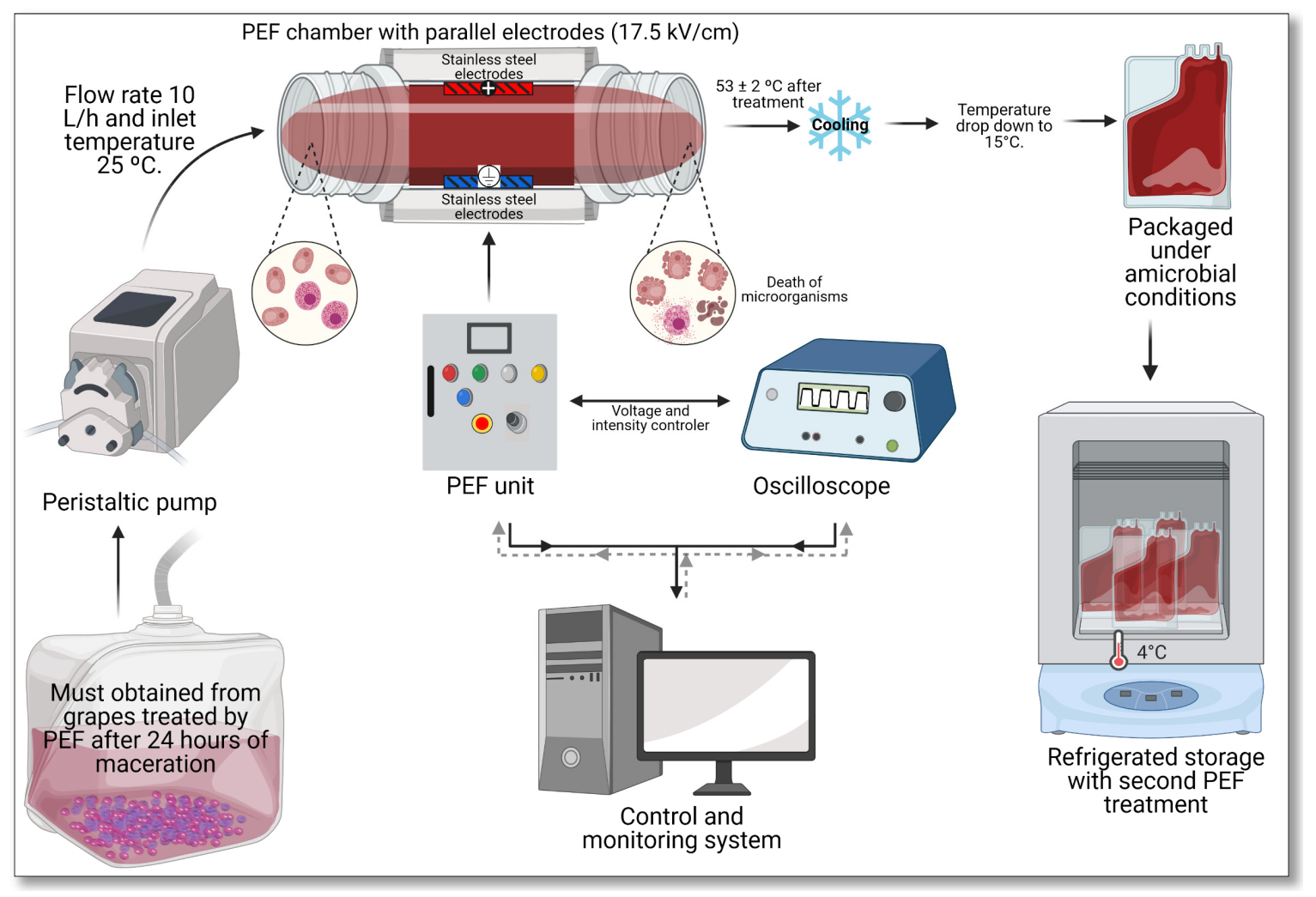

Figure 2. Schematic of the PEF processing of must.

Grenache must obtained from grapes treated by PEF and macerated for $24 \mathrm{~h}$ untreated $(8 \mathrm{~L})$ and PEF-treated (8 L) was used to evaluate the implantation of non-Saccharomyces starters.

The resulting must had a $\mathrm{pH}$ of $3.69 \pm 0.03$ in the PEF-treated must and $3.65 \pm 0.02$ in the untreated must, and a sugar content of $259 \pm 0.1 \mathrm{~g} / \mathrm{L}$ in the PEF-treated must and $255 \pm 0.2 \mathrm{~g} / \mathrm{L}$ in the untreated must. The $6.84 \mathrm{~L}$ of must were distributed into pre-sterilised $250 \mathrm{~mL}$ ISO flasks (190 mL per flask) using their own unsealed cap. Fermentations were carried out in triplicate at $19 \pm 0.1^{\circ} \mathrm{C}$.

\subsection{Yeast Used}

All yeast ferments were cultured in YPD (yeast extract, peptone, dextrose agar; 10:20:20 g/L) with two sequential steps of $24 \mathrm{~h}$ each to homogenise the populations, and then $2 \% v / v$ was inoculated into the must. This inoculation ratio produced a final population of $6 \log$ CFU/mL. Fermentation lasted for 20 days, and the basic oenological parameters were monitored daily using Fourier-transform infrared spectroscopy (FTIR) and enzymatic analysis. They were also placed in $100 \mathrm{~mL}$ sterile vials in triplicate and $60 \mathrm{~mL}$ of the (uninoculated) PEF-treated and untreated must was covered with a Müller valve to follow the fermentation.

The following non-Saccharomyces and Saccharomyces cerevisiae yeast strains were used in the fermentations: the Hanseniaspora vineae (Hv205) yeast strain used in this study was isolated by Professor Francisco Carrau (Facultad de Química, Universidad de la República, Montevideo, Uruguay); Lachancea thermotolerans (Lt) strain L31 (enotecUPM, ETSIAAB, UPM, Madrid, Spain); Torulaspora delbrueckii (Td) strain 291 (Lallemand Inc., Montreal, QC, Canada); Metschnikowia pulcherrima (Mp) strain Flavia ${ }^{\mathrm{TM} M P 346}$ (Lallemand Inc., Montreal, QC, Canada); Schizosaccharomyces pombe (Sp) strain 938 (IFI-CSIC, Madrid, Spain); together with the Saccharomyces cerevisiae (Sc) strain 7VA (enotecUPM, ETSIAAB, UPM, Madrid, Spain). 


\subsection{Fermentation Trials}

A single small-scale fermentation was performed in triplicate using the five nonSaccharomyces yeasts plus the Saccharomyces yeasts with and without PEF treatment. The procedure was, on one hand, a single fermentation with $\mathrm{Sc}$ used as control and sequential fermentations with $\mathrm{Lt} \rightarrow \mathrm{Sc}, \mathrm{Hv} \rightarrow \mathrm{Sc}, \mathrm{Td} \rightarrow \mathrm{Sc}, \mathrm{Mp} \rightarrow \mathrm{Sc}$ and $\mathrm{Sp} \rightarrow \mathrm{Sc}$, and on the other hand the same but with the untreated must used to evaluate the inoculum yield and determine the kinetics of the fermentations and their potency.

\subsection{Yeast Population Counts}

Inoculated yeast populations were measured by serial dilutions in YPD (yeast extract peptone, dextrose agar; 10:20:20 g/L), YGC (yeast extract, glucose, chloramphenicol agar; 5:20:0.2 g/L), lysine medium (Oxoid, Hampshire, UK), and CHROMagar ${ }^{\text {TM }}$ Candida (Conda, Barcelona, Spain). Samples were taken from the fermentations on days 0, 1, 4, 6 and 8, and on day 8 after sampling, Saccharomyces was inoculated. A lysine medium was selected for non-Saccharomyces and species identification was done in the differential chromogenic medium. With this method, a rigorous count was achieved in the inoculations.

\subsection{Oenological Parameters}

The equipment OenoFoss (FOSS Iberia, Barcelona, Spain) using Fourier-transform infrared spectroscopy (FTIR) was used to identify and quantify major compounds such as residual sugars, organic acids, total acidity (as tartaric acid) and volatile acidity (as acetic acid). This technique also estimates $\mathrm{pH}$ value. Lactic acid was measured enzymatically using a Y25 enzymatic autoanalyser (Biosystems, Barcelona, Spain). The absorbance at 280, 420, 520 and $620 \mathrm{~nm}$ was determined using an Agilent 8453 spectrophotometer (Agilent Technologies S.L., Madrid, Spain) and a $1 \mathrm{~mm}$ path length glass cuvette. The $\mathrm{pH}$ of each sample was measured with a Crison micropH $2000 \mathrm{pH}$ meter (HACH LANGE, Barcelona, Spain).

\subsection{Analysis of Fermentative Volatile Compounds Using GC-FID}

An Agilent Technologies 6850 gas chromatograph (Network GC System) coupled to a flame ionisation detector (GC-FID) was used for this analysis, as described in $[18,19]$. Samples were injected after filtration through $0.45 \mu \mathrm{m}$ cellulose methyl ester membrane filters (Phenomenex, Madrid, Spain). The column used was a DB-624 column. The total run time for each sample was $40 \mathrm{~min}$. The carrier gas used was hydrogen and the internal standard (4-methyl-2-pentanol, $500 \mathrm{mg} / \mathrm{L}$ ) (Fluka Chemie GmbH, Buchs, Switzerland). The detection limit was $0.1 \mathrm{mg} / \mathrm{L}$. The volatile compounds analysed with this technique were pre-calibrated with five-point calibration curves $\left(\mathrm{r}^{2}\right)$ and all compounds had an $\mathrm{r}^{2}>0.999$, except 2, 3-butanediol (0.991) and phenylethyl alcohol (0.994).

\subsection{Determination of Anthocyanins}

The following anthocyanins and pyranoanthocyanins were determined using an Agilent Technologies (Santa Clara, CA, USA) series 1200 HPLC chromatograph [20]. Concentrations were calculated with a calibration curve of malvidin-3-O-glucoside $\left(\mathrm{r}^{2}=0.9999\right.$, LOD $0.1 \mathrm{mg} / \mathrm{L}$ ). Injection volume $50 \mu \mathrm{L}$. Gradients of solvent A (water/formic acid, 95:5 v/v) and B (methanol/ formic acid, 95:5 v/v) were used in a reverse-phase Poroshell $120 \mathrm{C} 18$ column (Agilent Technologies, Santa Clara, CA, USA). The detection limit was $0.1 \mathrm{mg} / \mathrm{L}$.

\subsection{Sensory Analysis}

A panel of nine experienced tasters (aged between 25 and 60 years; four women and five men) evaluated the wines that had been bottled and refrigerated for three months. The blind tasting took place in the tasting room of the Department of Chemistry and Food Technology of the Universidad Politécnica de Madrid. The room was equipped with fluorescent lighting and the samples were presented in a random order. The wines (30 mL/tasting glass) were served at $12 \pm 2{ }^{\circ} \mathrm{C}$ in standard odourless tasting glasses. A 
glass of water was also provided to the panellists to clean the palate between samples. Before the generation of a consistent terminology by consensus, three visual attributes, seven for aroma and four for taste, were chosen to describe the wines. Panellists used a scale of 1 to 5 to rate the intensity of each attribute. Low values comprised "non-perceptible attributes" and, in contrast, high values featured "strongly perceptible attributes". Each panellist also evaluated the overall impression, taking into account olfactory and gustatory aspects, as well as the lack of defects. The tasting sheets also had a final blank space for any additional comments or observations on sensory notes or nuances not previously included as attributes.

\subsection{Statistical Analysis}

Statgraphics v.5 software (Graphics Software Systems, Rockville, MD, USA) was used to calculate means, standard deviation, and analysis of variance (ANOVA) and least significant differences (LSD). Significance was set at $p<0.05$ for the ANOVA matrix F value on the results of the sensory analysis. All treatments were evaluated in triplicate.

\section{Results}

\subsection{Effects of PEF on the Extraction of Grenache Must after $24 \mathrm{~h}$ of Maceration}

Table 1 shows the oenological parameters of the must obtained from grapes treated by PEF. These three values, the $\mathrm{pH}$, the ${ }^{\circ}$ Brix and the total acidity of the must are typical values for Grenache grapes and are not affected by the PEF treatment $[3,21]$. However, the electroporation of the grape must promoted the extraction of polyphenols from grape skins during maceration. The colour intensity, anthocyanin content, total polyphenolic index and tannin content of the must macerated with the crushed grape treated by PEF was 1.9, 2.2, 1.6 and 2 times higher than those in the must macerated with untreated crushed grape. Values of these indexes for the must macerated with PEF-treated grape must was in the range of some young wines, despite both the maceration temperature and time being much lower and shorter than those used for obtaining young wines [3,5,21,22].

Table 1. Oenological parameters of the Grenache must after $24 \mathrm{~h}$ of maceration at $5{ }^{\circ} \mathrm{C}$ with grapes treated by PEF.

\begin{tabular}{cc}
\hline \multicolumn{2}{c}{ Oenological Parameters } \\
\hline $\mathrm{pH}$ & $3.65 \pm 0.02$ \\
\hline Brix $(\mathrm{g} / \mathrm{L})$ & $25.5 \pm 0.21$ \\
\hline Total acidity $(\mathrm{g} / \mathrm{L})$ & $4.27 \pm 0.08$ \\
\hline Colour intensity & $17.64 \pm 0.10$ \\
\hline Total phenol index $(280 \mathrm{~nm})$ & $45.3 \pm 0.28$ \\
\hline Anthocyanins $(\mathrm{mg} / \mathrm{L})$ & $522.3 \pm 24.0$ \\
\hline Tannins $(\mathrm{mg} / \mathrm{L})$ & $104.5 \pm 13.8$ \\
\hline
\end{tabular}

\subsection{Antimicrobial Effect of PEF and Evolution of the Inoculated Population}

The musts were analysed before inoculation with selected non-Saccharomyces and Saccharomyces yeasts as a control to see the effects of PEFs. It was observed that the microbial load of the PEF-treated must with Saccharomyces and non-Saccharomyces PEF, which had received $17.5 \mathrm{kV} / \mathrm{cm}$, was 3-log, while the untreated must had a microbial load of 5-log Saccharomyces and 4-log non-Saccharomyces (Figure 3), verified with different culture media. 


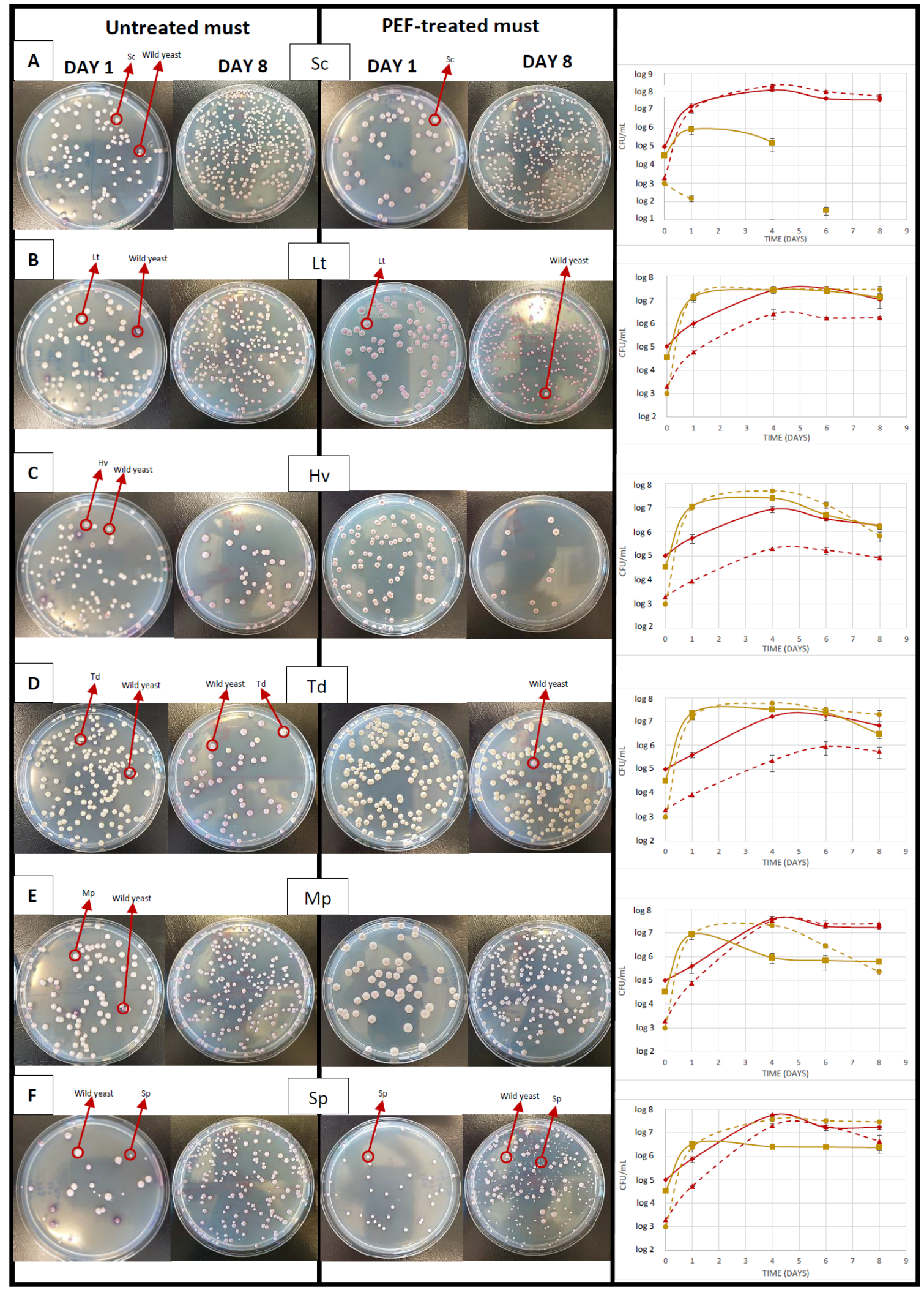

Figure 3. Days 1 and 8 plates of the different fermentations with and without PEF and CFU/mL counts throughout fermentation of untreated must with Saccharomyces (solid red line) and non-Saccharomyces yeasts (solid yellow line), in PEF-treated must with Saccharomyces yeasts (dashed red line) and non-Saccharomyces yeasts (dashed yellow line). Musts were inoculated with (A) S. cerevisiae, (B) L. thermotolerans, (C) H. vineae, (D) T. delbrueckii, (E) M. pulcherrima, and (F) S. pombe. Values are means with standard deviations (error bars) from three independent triplicates. 
Photos and monitoring of the population were taken once the musts were inoculated with the different yeasts (Figure 3) to study their implantation. The photos show the evolution of the population on days 1 and 8 after inoculation with the selected Sc, always using the same logarithm range, and also the differences in yeast types by colour and size, showing differences between inocula, untreated and PEF-treated must. For the untreated must (Figure 3A), we inoculated a Saccharomyces yeast and on day 1 we could already see differences between one must and another. In the PEF-treated must the Saccharomyces population was at 7-log and the non-Saccharomyces had been reduced to 2-log, while in the untreated must the Saccharomyces were 7-log and the non-Saccharomyces were 5-log. From that day on, the population of non-Saccharomyces began to decrease drastically due to the exponential fermentation of Saccharomyces, which reached a population of 8-log on day 4. The must inoculated with Lt (Figure 3B) has smaller colonies than the Saccharomyces colonies and its colour evolves from cream to pink. Rapid implantation of Lt is observed in both types of must on day 1, reaching 7-log; in the must with PEF the implantation of Saccharomyces was weaker. In the must inoculated with Hv (Figure 3C), which in the photos has an intense fuchsia peak in each colony, similar implantation to Lt with 7-log was observed on day 1 , although from day 5 there was a progressive decrease due to the increase in the population of Saccharomyces and the depletion of nutrients. As for the must with Td yeast (Figure 3D), the colour of the colonies is creamy-yellowish and a good implantation is seen but with a slight difference in that the evolution in the control has a greater population of wild Saccharomyces than Td on day 8. The colonies of the must inoculated with $\mathrm{Mp}$ (Figure 3E) are slightly larger than the rest and have a creamy-whitish colour. A good implantation was seen but, in both cases, once the wild Saccharomyces increased their population to a great extent, they displaced the $\mathrm{Mp}$, being clearly seen from day 4 of fermentation. The must inoculated with Sp yeast (Figure 3F), whose colonies are smaller and pale pink in colour, showed a worse implantation (6-log) and a better evolution and growth in the PEF-treated must.

\subsection{Oenological Parameters}

In the fermentation kinetics (Figure 4) of the must, differences in fermentative power between yeasts were observed. On day 4 of fermentation, there were three differentiated groups of yeasts: on the one hand, the musts inoculated with Sc had the highest alcoholic strength, which was between $12.4 \pm 0.00$ and $12.8 \pm 0.21 \% v / v$ being superior to the one that had received PEF treatment; in the second group, there were the inoculums with PEF-treated $\mathrm{Hv}, \mathrm{Td}$ and untreated inoculums $\mathrm{Lt}, \mathrm{Hv}, \mathrm{Td}, \mathrm{Mp}$ and $\mathrm{Sp}$, with an alcoholic degree between $8.5 \pm 0.25$ and $10.5 \pm 0.20 \% v / v$; finally, the third group comprised the inoculums with PEF-treated musts of Lt, Mp and Sp, with an alcoholic degree between $5.2 \pm 0.64$ and $7.4 \pm 0.35 \% v / v$. On day 6 , the musts inoculated with Sc had almost finished fermentation; a second group were between $12.2 \pm 0.15$ and $13.5 \pm 0.20 \% v / v$, and those with a slower fermentation were between $9.9 \pm 0.06$ and $10.5 \pm 0.21 \% v / v$. On day 8 , just before inoculating the Sc to facilitate the completion of fermentation, only three musts that had received PEF treatment were below 14 degrees alcohol (Lt, Mp and $\mathrm{Hv}$ ). Once the Sc was inoculated, the musts increased their alcohol content, although the must with Hv PEF could not finish fermentation and the fermentation with Lt PEF also had a few grams of residual sugars. 


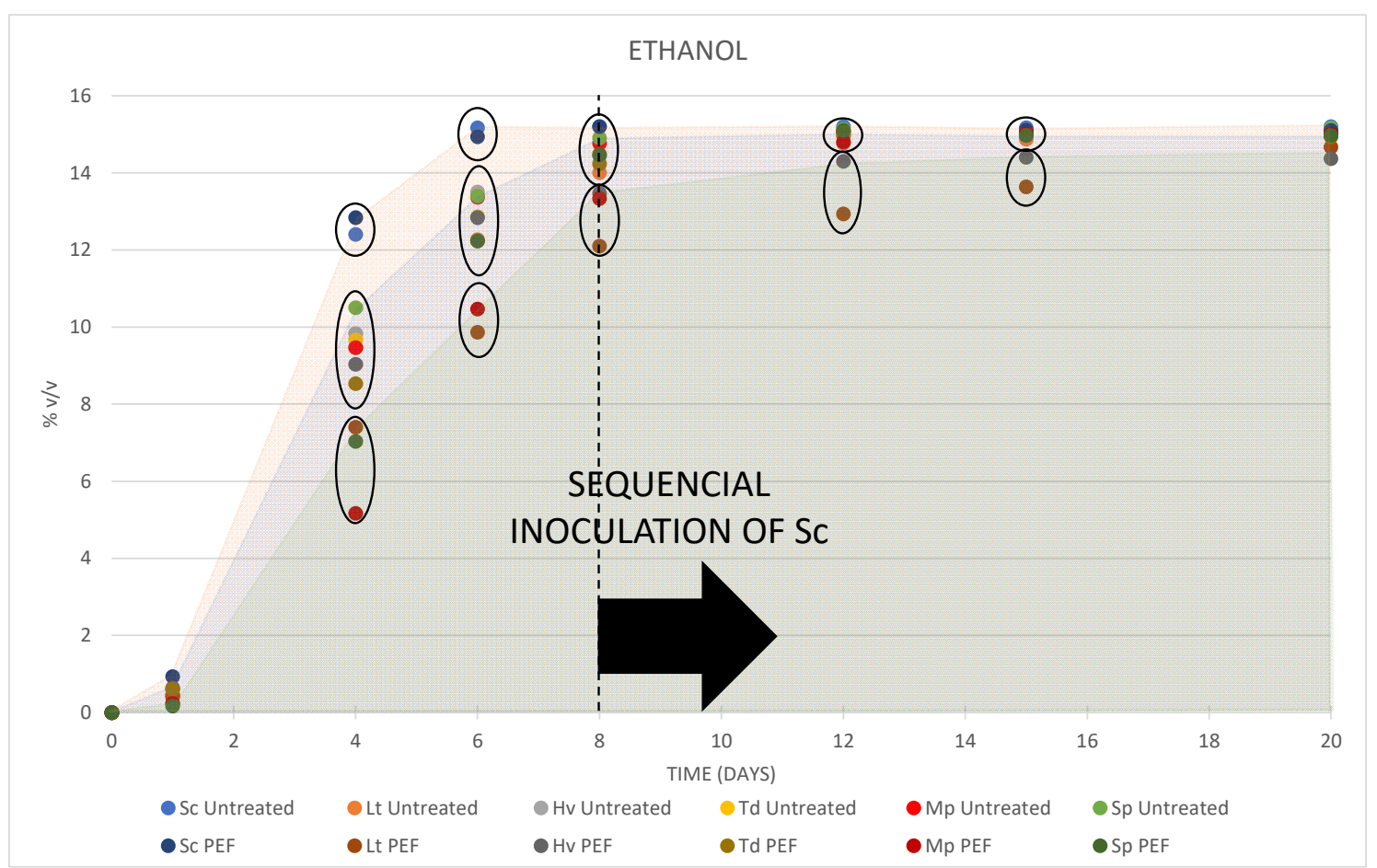

Figure 4. Evolution of the alcoholic strength produced during the fermentation of the different inoculations. The three colours in the figure show the fermentative power before sequential inoculation of the Sc.

For a better understanding of the oenological data in Table 2, the fermentations with the Sc inoculum had very similar parameters throughout the fermentation. The PEF-treated must with the Lt inoculum was very different from the untreated must: the PEF-treated must with the Lt had a lower alcohol content $(14.7 \pm 0.1 \% v / v)$, a higher total acidity $(5.37 \pm 0.29 \mathrm{~g} / \mathrm{L})$, and a significantly lower $\mathrm{pH}(3.19 \pm 0.09)$. The same path followed the fermentation with PEF-treated must with the $\mathrm{Hv}$, where it was seen that it could not finish fermentation $(14.37 \pm 0.12 \% v / v)$ and ended with a residual sugar of $15.73 \pm 0.7 \mathrm{~g} / \mathrm{L}$. With respect to $\mathrm{Td}, \mathrm{Mp}$ and $\mathrm{Sp}$, all were slower on day 8 of fermentation than those that had received PEF, but all finished with fairly similar parameters. It should be noted that all untreated must had lower sugars on day 8 of fermentation due to the rapid implantation of wild yeasts.

\subsection{Lactic and Malic Acid}

At the end of fermentation, the high production of lactic acid (Figure 5A) was observed in PEF-treated must with Lt, giving $3.62 \pm 0.84 \mathrm{~g} / \mathrm{L}$, while in the untreated must with $\mathrm{Lt}$ it only reached $0.80 \pm 0.09 \mathrm{~g} / \mathrm{L}$. On the other hand, the malic acid (Figure 5B) obtained can be grouped in three groups from day 4 , becoming more noticeable from day 8 : in the first group, in the upper part, six musts are seen with a malic acidity on day 20 between $0.98 \pm 0.04$ and $1.29 \pm 0.09 \mathrm{~g} / \mathrm{L}$; in the second group, in the middle of the figure, the data are between $0.55 \pm 0.04$ and $0.83 \pm 0.05 \mathrm{~g} / \mathrm{L}$; finally, the third group in the lower part are the Sp yeasts giving $0.10 \pm 0.02$ and $0.00 \pm 0.00 \mathrm{~g} / \mathrm{L}$, which are always below the one that had received PEF. 
Table 2. Oenological parameters of the different fermentations before sequential inoculation with Sc (day 8) and on the last day of analysis (day 30). Values are means with standard deviations, $n=3$. Values with the same letter in the same column are not significantly different $(p<0.05)$.

\begin{tabular}{|c|c|c|c|c|c|c|c|c|c|c|}
\hline \multirow{2}{*}{$\begin{array}{l}\text { Parameters } \\
\text { Yeast/Days }\end{array}$} & \multicolumn{2}{|c|}{ Ethanol $(\% v / v)$} & \multicolumn{2}{|c|}{ Total Acidity (g/L) } & \multicolumn{2}{|c|}{ Volatile Acidity (g/L) } & \multicolumn{2}{|c|}{ Glucose/Fructose (g/L) } & \multicolumn{2}{|c|}{$\mathrm{pH}$} \\
\hline & 8 & 20 & 8 & 20 & 8 & 20 & 8 & 20 & 8 & 20 \\
\hline Sc Untreated & $15.20 \pm 0.00 \mathrm{~g}$ & $15.20 \pm 0.10 \mathrm{f}$ & $4.33 \pm 0.06 \mathrm{e}$ & $3.87 \pm 0.06 c$ & $0.07 \pm 0.00 \mathrm{a}$ & $0.09 \pm 0.01 \mathrm{a}$ & $0.30 \pm 0.00 \mathrm{a}$ & $0.13 \pm 0.23 \mathrm{ab}$ & $3.38 \pm 0.01 \mathrm{~cd}$ & $3.55 \pm 0.01 \mathrm{def}$ \\
\hline Sc PEF & $15.20 \pm 0.10 \mathrm{~g}$ & $15.10 \pm 0.10 \mathrm{~d}$ ef & $4.37 \pm 0.06 \mathrm{ef}$ & $3.93 \pm 0.06 \mathrm{~cd}$ & $0.08 \pm 0.02 \mathrm{ab}$ & $0.09 \pm 0.01 \mathrm{ab}$ & $0.00 \pm 0.00 \mathrm{a}$ & $0.00 \pm 0.00 \mathrm{a}$ & $3.40 \pm 0.01 \mathrm{de}$ & $3.55 \pm 0.01 \mathrm{def}$ \\
\hline Lt Untreated & $14.00 \pm 0.00 \mathrm{c}$ & $14.97 \pm 0.06 \mathrm{~cd}$ & $4.90 \pm 0.10 \mathrm{~g}$ & $4.77 \pm 0.06 \mathrm{f}$ & $0.17 \pm 0.01 \mathrm{e}$ & $0.15 \pm 0.01 \mathrm{c}$ & $23.60 \pm 1.90 \mathrm{e}$ & $0.30 \pm 0.36 \mathrm{ab}$ & $3.30 \pm 0.02 \mathrm{~b}$ & $3.38 \pm 0.01 \mathrm{~b}$ \\
\hline Lt PEF & $12.10 \pm 0.10 \mathrm{a}$ & $14.70 \pm 0.10 \mathrm{~b}$ & $5.50 \pm 0.17 \mathrm{~h}$ & $5.37 \pm 0.29 \mathrm{~g}$ & $0.33 \pm 0.03 \mathrm{~h}$ & $0.34 \pm 0.06 \mathrm{e}$ & $51.10 \pm 0.87 \mathrm{~g}$ & $3.47 \pm 0.85 \mathrm{f}$ & $3.13 \pm 0.02 \mathrm{a}$ & $3.19 \pm 0.09 \mathrm{a}$ \\
\hline Hv Untreated & $14.43 \pm 0.15 \mathrm{e}$ & $15.03 \pm 0.12$ cde & $4.00 \pm 0.00 \mathrm{bc}$ & $3.93 \pm 0.06 \mathrm{~cd}$ & $0.25 \pm 0.02 \mathrm{~g}$ & $0.23 \pm 0.02 \mathrm{~d}$ & $18.17 \pm 3.25 \mathrm{~d}$ & $0.80 \pm 0.17 \mathrm{bc}$ & $3.44 \pm 0.01 \mathrm{fg}$ & $3.49 \pm 0.00 \mathrm{c}$ \\
\hline Hv PEF & $13.47 \pm 0.15 \mathrm{~b}$ & $14.37 \pm 0.12 \mathrm{a}$ & $3.63 \pm 0.15 \mathrm{a}$ & $3.37 \pm 0.06 \mathrm{a}$ & $0.31 \pm 0.02 \mathrm{~h}$ & $0.31 \pm 0.01 \mathrm{e}$ & $33.00 \pm 2.52 \mathrm{f}$ & $15.73 \pm 0.70 \mathrm{~g}$ & $3.49 \pm 0.02 \mathrm{~h}$ & $3.58 \pm 0.01 \mathrm{ef}$ \\
\hline Td Untreated & $14.50 \pm 0.10 \mathrm{e}$ & $15.03 \pm 0.06 \mathrm{cde}$ & $4.33 \pm 0.06 \mathrm{e}$ & $4.13 \pm 0.06 \mathrm{e}$ & $0.11 \pm 0.02 \mathrm{~cd}$ & $0.11 \pm 0.00 \mathrm{ab}$ & $13.33 \pm 0.45 \mathrm{c}$ & $1.90 \pm 0.35 \mathrm{de}$ & $3.42 \pm 0.02 \mathrm{ef}$ & $3.47 \pm 0.01 \mathrm{c}$ \\
\hline Td PEF & $14.23 \pm 0.15 \mathrm{~d}$ & $14.93 \pm 0.06 \mathrm{c}$ & $3.90 \pm 0.17 \mathrm{~b}$ & $3.60 \pm 0.17 \mathrm{~b}$ & $0.12 \pm 0.02 \mathrm{~cd}$ & $0.11 \pm 0.01 \mathrm{ab}$ & $16.80 \pm 3.02 \mathrm{~cd}$ & $2.13 \pm 0.21 \mathrm{e}$ & $3.47 \pm 0.02 \mathrm{~h}$ & $3.59 \pm 0.02 \mathrm{f}$ \\
\hline Mp Untreated & $14.77 \pm 0.06 \mathrm{f}$ & $15.10 \pm 0.00 \mathrm{def}$ & $4.50 \pm 0.00 \mathrm{f}$ & $4.20 \pm 0.00 \mathrm{e}$ & $0.13 \pm 0.01 \mathrm{~d}$ & $0.12 \pm 0.01 \mathrm{abc}$ & $8.90 \pm 1.55 b$ & $1.23 \pm 0.87 \mathrm{~cd}$ & $3.36 \pm 0.01 \mathrm{c}$ & $3.45 \pm 0.01 \mathrm{c}$ \\
\hline Mp PEF & $13.33 \pm 0.06 \mathrm{~b}$ & $15.00 \pm 0.10 \mathrm{~cd}$ & $4.13 \pm 0.06 \mathrm{~cd}$ & $4.10 \pm 0.00 \mathrm{de}$ & $0.21 \pm 0.01 \mathrm{f}$ & $0.15 \pm 0.01 \mathrm{c}$ & $32.07 \pm 0.93 \mathrm{f}$ & $0.80 \pm 0.44 \mathrm{bc}$ & $3.40 \pm 0.01 \mathrm{de}$ & $3.49 \pm 0.00 \mathrm{c}$ \\
\hline Sp Untreated & $14.90 \pm 0.10 \mathrm{f}$ & $15.17 \pm 0.12$ ef & $3.70 \pm 0.00 \mathrm{a}$ & $3.37 \pm 0.06 \mathrm{a}$ & $0.10 \pm 0.01 \mathrm{bc}$ & $0.12 \pm 0.01 \mathrm{bc}$ & $7.07 \pm 4.80 \mathrm{~b}$ & $0.00 \pm 0.00 \mathrm{a}$ & $3.45 \pm 0.01 \mathrm{~g}$ & $3.54 \pm 0.01 \mathrm{~d}$ \\
\hline Sp PEF & $14.47 \pm 0.06 \mathrm{e}$ & $14.97 \pm 0.12 \mathrm{~cd}$ & $4.17 \pm 0.06 \mathrm{~d}$ & $3.63 \pm 0.06 \mathrm{~b}$ & $0.22 \pm 0.02 \mathrm{f}$ & $0.21 \pm 0.02 \mathrm{~d}$ & $9.40 \pm 1.78 \mathrm{~b}$ & $0.03 \pm 0.06 \mathrm{ab}$ & $3.40 \pm 0.02 \mathrm{de}$ & $3.54 \pm 0.00 \mathrm{de}$ \\
\hline
\end{tabular}

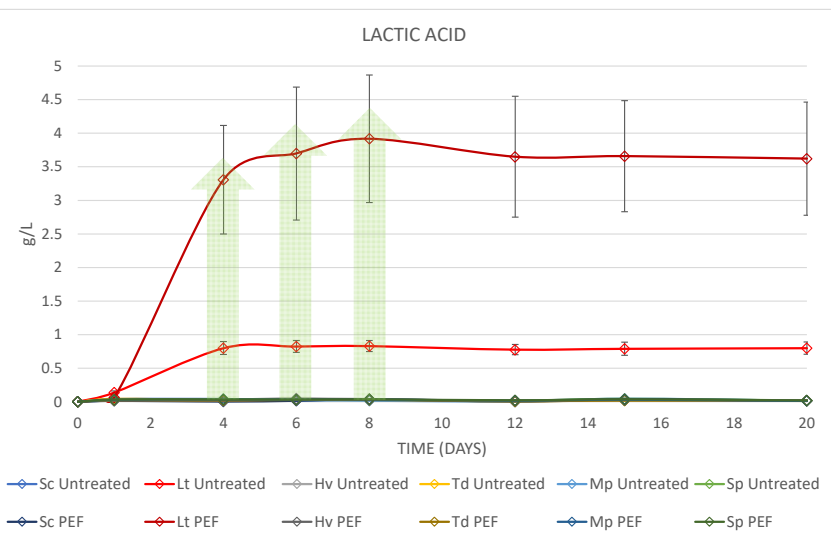

(A)

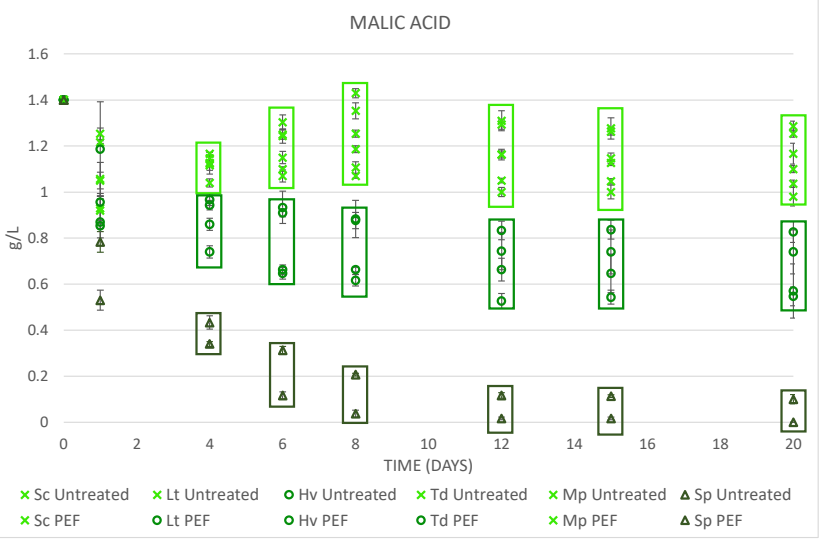

(B)

Figure 5. (A) Lactic acid produced in the fermentations. (B) Malic acid at the end of fermentation divided into three groups by amount of malic acid produced. Values are means $\pm \mathrm{sd}(n=3)$.

\subsection{Fermentative Volatiles}

To evaluate the impact of these non-Saccharomyces yeasts on the PEF-treated and untreated must, we focused on three different categories: higher alcohols, carbonyl compounds, and total esters. Analyses were carried out on days 8 and 20 to evaluate their evolution and to compare between the two musts/wines. In the higher alcohols on day 8 of fermentation before inoculation of Sc (Figure 6A), it was observed that except for Sc $\operatorname{PEF}(348.07 \pm 20.37 \mathrm{mg} / \mathrm{L})$ and Sp PEF $(243.65 \pm 13.89 \mathrm{mg} / \mathrm{L})$, all the other fermentations exceeded $350 \mathrm{mg} / \mathrm{L}$, which can generate undesirable wine aromas, and in all cases, the higher alcohols in the PEF-treated musts were lower or equal. These high levels were mainly produced by 3-methyl-1-butanol, which in no case exceeded $300 \mathrm{mg} / \mathrm{L}$, and by isobutanol, which was in all musts between 75 and $125 \mathrm{mg} / \mathrm{L}$. It is interesting to note that 1-propanol in the must inoculated with Lt untreated and PEF-treated almost doubled its amount compared to the others, having between $79.84 \pm 3.39$ and $74.85 \pm 5.20 \mathrm{mg} / \mathrm{L}$.

The carbonyl compounds (Figure 6A), which include acetoin and diacetyl, were slightly higher in those that were PEF-treated, especially with yeast $\mathrm{Hv}$ that generated $30.63 \pm 3.73 \mathrm{mg} / \mathrm{L}$ of acetoin.

The total esters (Figure 6A), which include ethyl acetate, isobutyl acetate, ethyl butyrate, ethyl lactate, isoamyl acetate and 2-phenylethyl acetate, showed that those that were PEF-treated had less ethyl acetate than the untreated ones, the must with the highest amount $(59.80 \pm 4.13 \mathrm{mg} / \mathrm{L})$ being the Sp untreated one. In all the other fermentations the ethyl acetate was between 15 and $35 \mathrm{mg} / \mathrm{L}$. The concentration of 2-phenylethyl acetate was much higher in the Lt untreated and PEF-treated must, being $28.71 \pm 0.77$ and $88.42 \pm 10.14 \mathrm{mg} / \mathrm{L}$ respectively. 


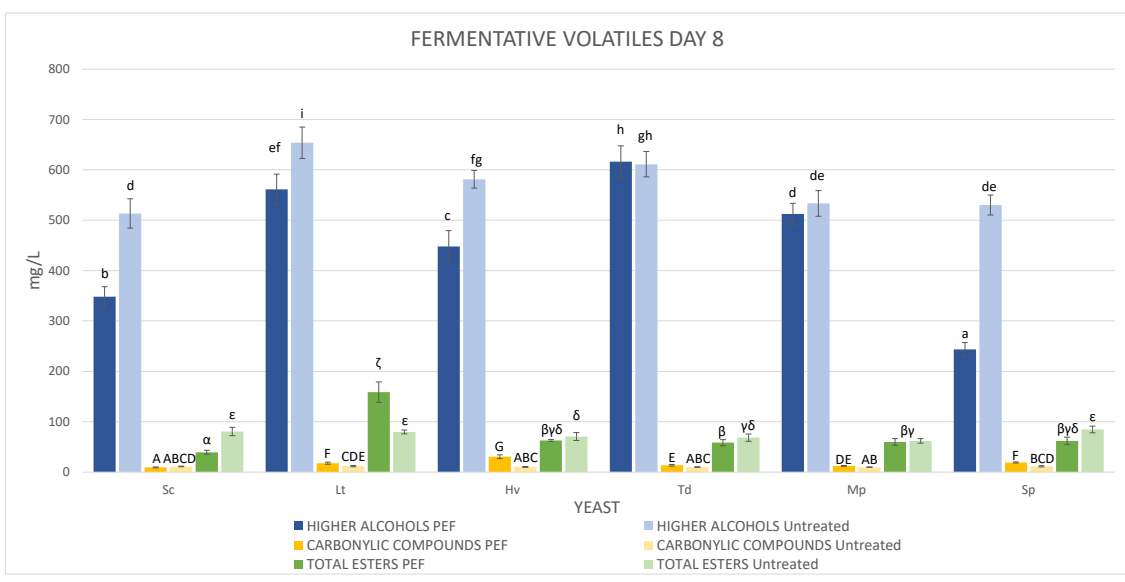

(A)

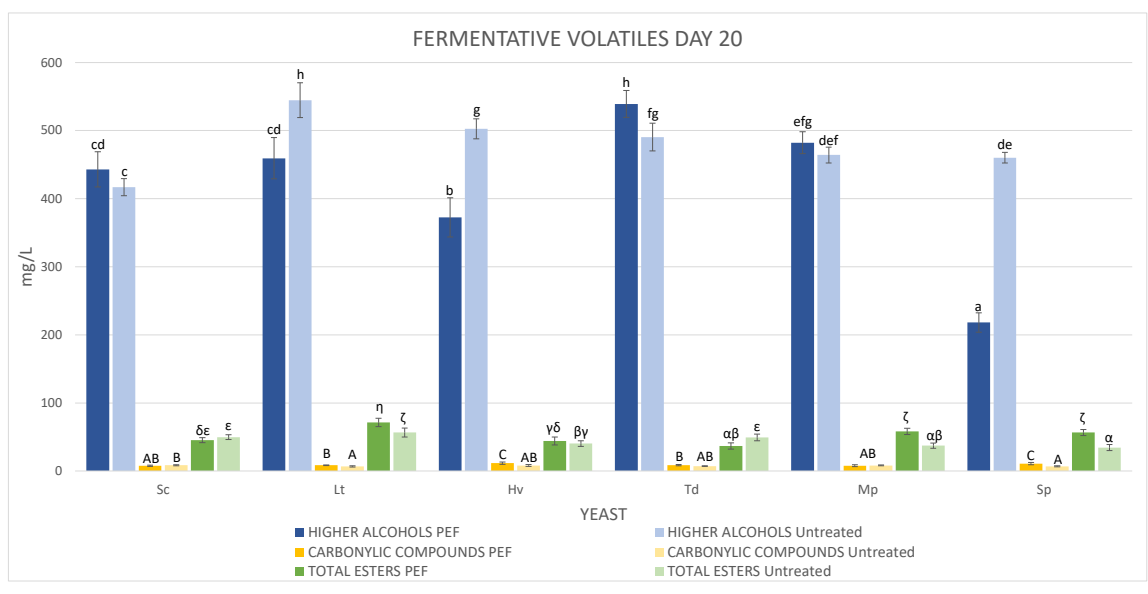

(B)

Figure 6. Fermentative volatiles in wines obtained from untreated and PEF-treated musts/wines. (A) Day 8 and (B) day 20. Values are means $\pm \mathrm{sd}(n=3)$. A different letter (lowercase, capital and Greek letters) for the same category of volatiles means significant differences $(p<0.05)$.

On the other hand, on day 20, at the end of fermentation, it was observed that the higher alcohols (Figure 6B) remained elevated except for Sp PEF with $218.28 \pm 14.26 \mathrm{mg} / \mathrm{L}$, which did not increase. Carbonyl compounds decreased in general although the PEFtreated must with $\mathrm{Hv}(11.63 \pm 1.68 \mathrm{mg} / \mathrm{L})$ was still higher than the rest. Finally, the esters decreased in general, all being below $72 \mathrm{mg} / \mathrm{L}$, although it should be noted that 2-phenylethyl acetate was twice as high $(14.64 \pm 1.31 \mathrm{mg} / \mathrm{L})$ in the PEF-treated must with Hv compared to the rest of the yeasts and treatments, and ethyl lactate in the Lt PEF was $47.19 \pm 4.00 \mathrm{mg} / \mathrm{L}$, the highest in all cases. It is worth mentioning that 3-ethoxy-1propanol was higher in the Td PEF on day $8(8.05 \pm 1.61 \mathrm{mg} / \mathrm{L})$ than in the control $(2.92$ $\pm 0.72 \mathrm{mg} / \mathrm{L}$ ). In both cases, at the end of fermentation, this compound decreased; in the control it disappeared completely and in the PEF it decreased to $3.17 \pm 0.58 \mathrm{mg} / \mathrm{L}$.

\subsection{Anthocyanins and Colour}

The typical colour of red wines is due to the presence of anthocyanins and their derivatives. Figure 7A shows the total anthocyanin content of grapes. This fraction includes acylated and non-acylated anthocyanins, and anthocyanins acylated from free anthocyanins with acetic and p-coumaric acid. In general, total anthocyanins were always higher in wines with PEF-treated must, except for the coumaroylate fraction. The mean of the glucosylated fraction in the PEF-treated must was $202.17 \pm 2.49 \mathrm{mg} / \mathrm{L}$ while in the untreated must it was $196.97 \pm 0.83 \mathrm{mg} / \mathrm{L}$, with malvidin-3-glucoside being the 
main anthocyanin, representing practically the totality of monomeric anthocyanins in all wines. The mean of the acetylated fraction was $4.55 \pm 0.11 \mathrm{mg} / \mathrm{L}$ in the PEF-treated must and $4.35 \pm 0.08 \mathrm{mg} / \mathrm{L}$ in the untreated must, and the p-coumaroylated fraction was $12.91 \pm 0.70 \mathrm{mg} / \mathrm{L}$ in the PEF-treated must and $13.67 \pm 0.19 \mathrm{mg} / \mathrm{L}$ in the untreated must. Concerning the vitisins obtained (Figure $7 \mathrm{~B}$ ), on the one hand the mean of vitisins $\mathrm{B}$ was higher in those that were PEF-treated $(0.47 \pm 0.03 \mathrm{mg} / \mathrm{L})$, while the mean of vitisins A was also higher in those that were PEF-treated $(2.46 \pm 0.09 \mathrm{mg} / \mathrm{L})$, the highest value being that of the yeast Sp PEF with $4.3 \pm 0.15 \mathrm{mg} / \mathrm{L}$. It was observed (Figure 7C) that the wines that were PEF-treated and untreated with Sc produced vinyl epicatechins $(0.18 \pm 0.01$ and $0.13 \pm 0.00 \mathrm{mg} / \mathrm{L}$ ) lower amounts were observed in the untreated $\mathrm{Lt}$ and $\mathrm{Sp}$ yeasts and untreated and PEF-treated Mp.

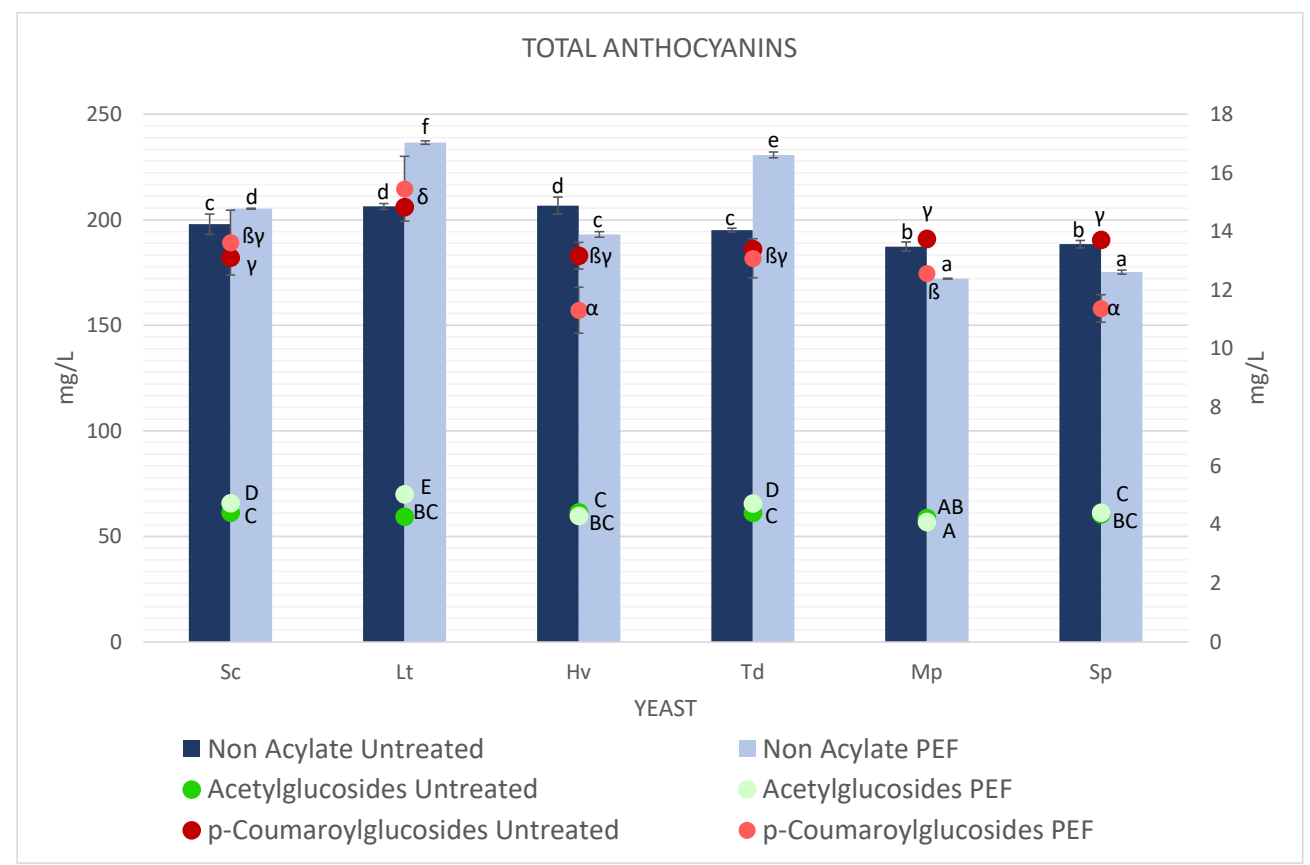

(A)

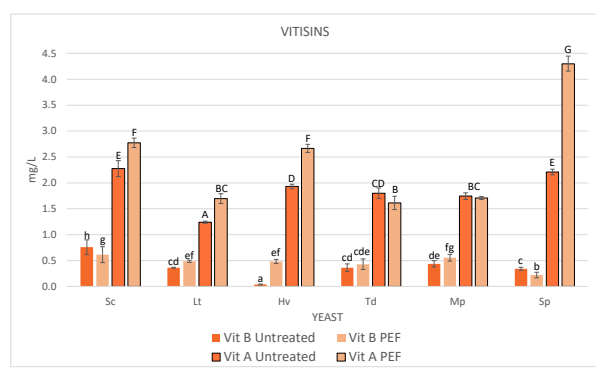

(B)

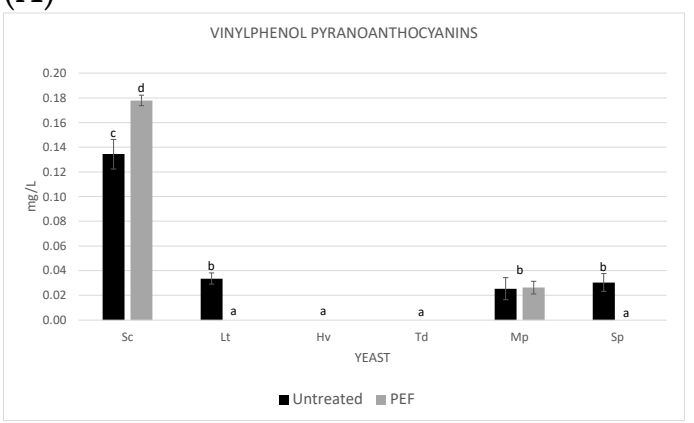

(C)

Figure 7. (A) Total anthocyanins divided into three groups of untreated and PEF-treated wine. (B) Vitisins A and B. (C) Vinylphenol pyranoanthocyanins. Values are means $\pm \mathrm{sd}(n=3)$. A different letter (lowercase, capital and Greek letters) for the same category of anthocyanins means significant differences $(p<0.05)$. 
Colour intensity, hue and total polyphenols index (TPI) were determined at days 0 and 20 (Table 3) to evaluate colour changes. A slightly higher IPT was observed in the musts with PEF, as well as slightly lower colour intensity. On the other hand, the highest colour intensity in the wines was in both cases for the Lt yeast, due to the effect of a lower $\mathrm{pH}$. The latter was higher in the control, and the $\mathrm{Hv}$ and $\mathrm{Mp}$ control were the highest in terms of hue. Finally, it was observed that the mean IPTs in both cases were practically the same, PEF $27.14 \pm 0.28$ and control $27.24 \pm 0.36$.

Table 3. Parameters of colour intensity, tonality and total polyphenols index (TPI) measured before inoculation (day 0 ) and on the last day of fermentation (day 20). Values are means $\pm s d(n=3)$. A different letter for the same day means significant differences $(p<0.05)$.

\begin{tabular}{|c|c|c|c|c|c|c|}
\hline \multirow{2}{*}{$\begin{array}{l}\text { Parameters } \\
\text { Yeast/Day }\end{array}$} & \multicolumn{2}{|c|}{ Colour Intensity } & \multicolumn{2}{|c|}{ Tonality } & \multicolumn{2}{|c|}{ TPI } \\
\hline & Day 0 & Day 20 & Day 0 & Day 20 & Day 0 & Day 20 \\
\hline Sc Untreated & \multirow{6}{*}{$17.64 \pm 0.10 b$} & $6.02 \pm 0.26 \mathrm{~d}$ & \multirow{6}{*}{$6.33 \pm 0.10 a$} & $5.52 \pm 0.30 c$ & \multirow{6}{*}{$45.9 \pm 0.10 \mathrm{a}$} & $27.3 \pm 0.82 \mathrm{cdef}$ \\
\hline Lt Untreated & & $6.94 \pm 0.20 \mathrm{e}$ & & $4.93 \pm 0.27 \mathrm{a}$ & & $24.7 \pm 0.49 \mathrm{a}$ \\
\hline Hv Untreated & & $5.99 \pm 0.15 \mathrm{~d}$ & & $6.44 \pm 0.18 \mathrm{~h}$ & & $27.7 \pm 0.31 \mathrm{def}$ \\
\hline Td Untreated & & $5.74 \pm 0.12 \mathrm{bcd}$ & & $5.70 \pm 0.14 \mathrm{de}$ & & $27.2 \pm 0.35$ cde \\
\hline Mp Untreated & & $6.81 \pm 0.21 \mathrm{e}$ & & $6.59 \pm 0.26 \mathrm{~h}$ & & $28.8 \pm 0.12 \mathrm{~g}$ \\
\hline Sp Untreated & & $5.71 \pm 0.17 \mathrm{bcd}$ & & $5.46 \pm 0.25 \mathrm{bc}$ & & $27.0 \pm 0.10 \mathrm{c}$ \\
\hline Sc PEF & \multirow{6}{*}{$16.92 \pm 0.20 \mathrm{a}$} & $5.05 \pm 0.05 \mathrm{a}$ & \multirow{6}{*}{$6.32 \pm 0.20 \mathrm{a}$} & $5.31 \pm 0.06 b$ & \multirow{6}{*}{$47.9 \pm 0.20 b$} & $26.1 \pm 0.31 b$ \\
\hline Lt PEF & & $6.09 \pm 0.08 \mathrm{~d}$ & & $5.54 \pm 0.08 \mathrm{~cd}$ & & $27.1 \pm 0.39 \mathrm{~cd}$ \\
\hline Hv PEF & & $5.88 \pm 0.07 \mathrm{~cd}$ & & $6.15 \pm 0.08 \mathrm{~g}$ & & $28.4 \pm 0.39 \mathrm{fg}$ \\
\hline Td PEF & & $5.41 \pm 0.03 \mathrm{ab}$ & & $5.57 \pm 0.04$ cde & & $26.1 \pm 0.29 b$ \\
\hline Mp PEF & & $5.75 \pm 0.25 \mathrm{bcd}$ & & $5.72 \pm 0.29 \mathrm{e}$ & & $27.8 \pm 0.11$ ef \\
\hline Sp PEF & & $5.46 \pm 0.22 \mathrm{abc}$ & & $5.97 \pm 0.26 \mathrm{f}$ & & $28.0 \pm 0.22 \mathrm{f}$ \\
\hline
\end{tabular}

\subsection{Sensory Analysis}

The wines were sensorially evaluated for possible differences (Figure 8). In general there were no major differences between the PEF treated and untreated, however, tasters detected a greater colour intensity in the Sc PEF $(4.00 \pm 0.71)$ along with a greater hue ( $2.78 \pm 0.83)$, perhaps due to greater oxidation; on the other hand, the lowest hue, i.e., bluer tones, was found in the Sp PEF with $1.67 \pm 0.87$. Turbidity was minimal since an effective and efficient filtering process was carried out. In general, in terms of aromatic intensity and quality, the wines with PEF-treated scored higher. The wines were slightly herbaceous, a bit floral and with a medium level of fruitiness, the lowest being the Mp untreated wines $(1.67 \pm 0.87)$ and the highest the Sp PEF $(3.11 \pm 1.36)$. It was seen that the most oxidised samples were those fermented with Sc, perhaps due to faster fermentation. Although the Hv PEF was the one with the highest residual sugar, it was not significantly detected by the tasters; however, the acidity parameter was detected in both cases with the Lt yeast and Lt untreated yeast with $3.56 \pm 0.88$ and Lt PEF $4.00 \pm 0.50$. In the overall perception of taste, Sp PEF ( $3.22 \pm 1.09)$ was superior to the rest, although with a greater deviation. However, as mentioned above, there were no major differences, but overall the tasters found the wines with PEF to be more complex, with more aromatic intensity, more fruit and acidity, all due to better implantation of the non-Saccharomyces yeasts that generate a slight increase of desirable metabolites in the wines. 


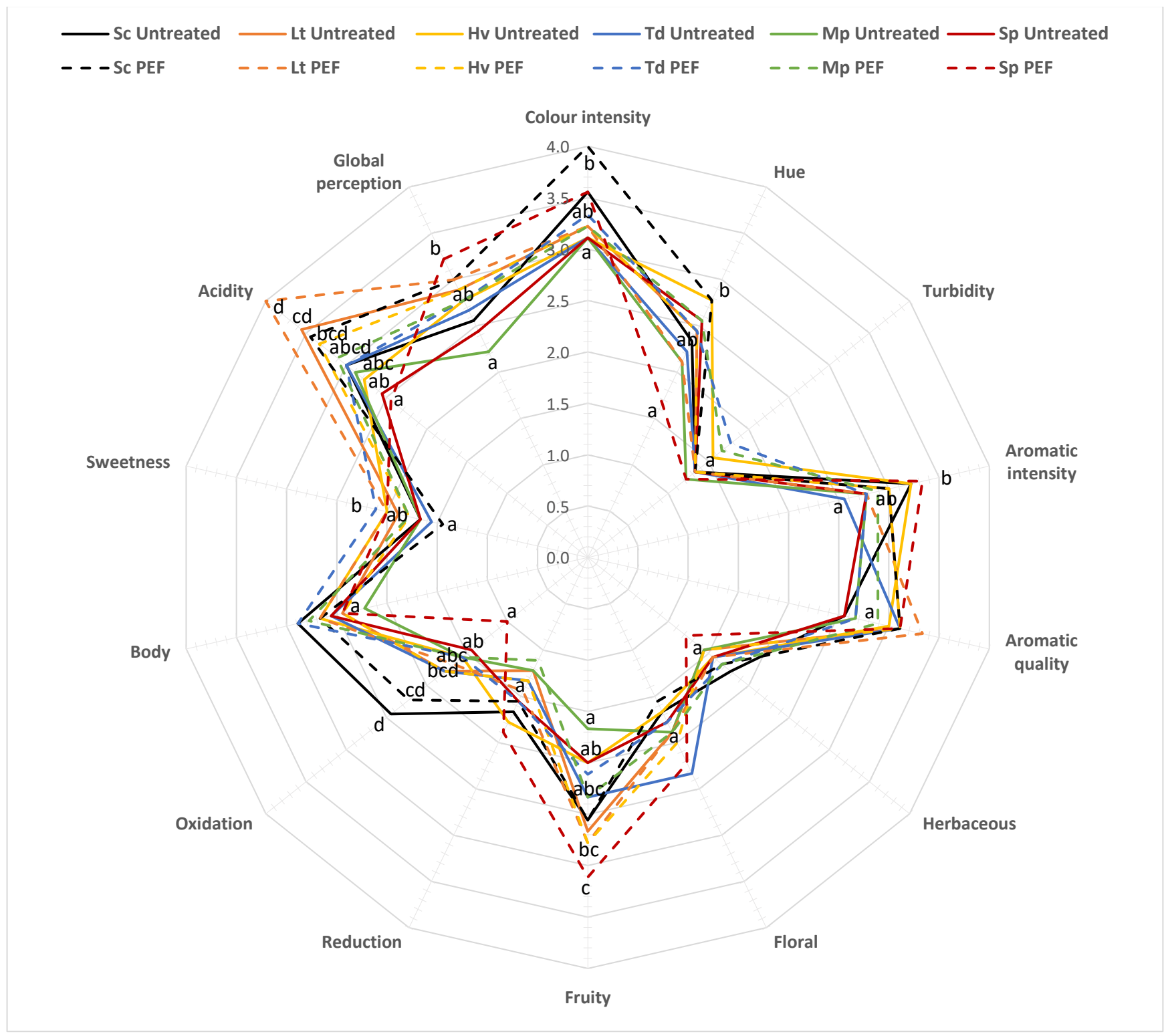

Figure 8. Sensory analysis of wines. The values are the average from nine tasters. The same attributes with the same letter are not significantly different $(p<0.05)$.

For a complete understanding of the sensory analysis (Supplementary Table S1), an ANOVA statistical analysis was performed separating by each variability factor: must treatment with PEF/no must treatment and fermentative biotechnology (6 yeasts evaluated).

It was observed that in colour intensity there were no significant differences due to pretreatment of the must with PEF, but there were significant differences depending on the fermentative biotechnology used. In terms of hue, there were significant differences due to pretreatment of the must with PEF in the Sp yeasts. It was also observed that in the fruit parameter there were significant differences due to pretreatment of the must with PEF in the Sp yeast and also significant differences depending on the fermentation biotechnology used. Oxidation had no significant differences due to pretreatment of the must with PEF, but did have significant differences depending on the fermentation biotechnology used. In the sweetness parameter, there were no significant differences due to pretreatment of the must with PEF, but there were significant differences depending on the fermentation biotechnology used. Finally, there were no significant differences in 
acidity due to pretreatment of the must with PEF, but there were significant differences depending on the fermentation biotechnology used.

\section{Discussion}

In this investigation, the ability of PEF to improve mass transfer and for use in microbial decontamination at lower temperatures than those used in thermal processing was used to investigate the effect of non-Saccharomyces starters in the oenological and sensorial characteristics of red wine. In the first step, PEF treatment was applied to electroporate the cells of the grape skins to accelerate the extraction of polyphenols. This effect has been widely described in the literature. However, most of the studies that have demonstrated the effect of PEF in improving polyphenol release have been conducted applying treatments of low energy $(<10 \mathrm{~kJ} / \mathrm{kg})$ and extending maceration for several days at room temperature [23]. In this investigation, according to results previously obtained by [21], the total specific energy of the treatment was significantly increased to obtain a large degree of electroporation that resulted in a high concentration of polyphenols in the must within a few hours of maceration at $5{ }^{\circ} \mathrm{C}$ (this temperature is optimal to keep the must and the proliferation of micro-organisms to a minimum).

Red must obtained from crushed grape treated by PEF was decontaminated by applying a second PEF treatment at a higher electric field strength $(17.5 \mathrm{kV} / \mathrm{cm})$ than those applied to the grape must $(5 \mathrm{kV} / \mathrm{cm})$. It is well known that, as microbial cells are smaller than cells of plant tissues, the external electric field required to achieve the critical transmembrane potential for manifestation of electroporation is higher [24]. Several studies have reported that PEF could be an alternative to the addition of $\mathrm{SO}_{2}$ due to its effectiveness to inactivate bacteria and yeast in the must of white grapes in winemaking [25].

It was observed in the population counts made on plates that in all cases the implantation of selected non-Saccharomyces yeasts was better in the must that had received PEF, due to the inactivation of part of their wild yeasts $[12,26]$.

Due to this differentiation in yeast implantation, the fermentations that had received PEF were slightly slower, particularly Hv, probably due to the lack of nutrients such as thiamine $[27,28]$ and also $L t$ due to a considerable increase in acidity $[14,29]$. Volatile acidity with Td yeast was the lowest in both cases, as also seen in other studies [30-32]. It should be noted that Lt yeast is capable of producing large amounts of lactic acid depending on different factors $[29,33]$. This amount of lactic acid was produced around day 6 , as shown in previous studies $[14,34]$ and was much higher in the must that had received PEF due to its better implantation. On the other hand, the Sp yeast in both treatments reduced the amount of malic acid to zero (with a greater reduction in the Sp PEF due to its better implantation) [35] and, in general, it was observed that the non-Saccharomyces yeasts that had received PEF had produced less malic acid.

As for volatile compounds, each yeast contributes its metabolites, which are significant in improving wine complexity [36-38]. On the one hand, the higher alcohols on both days 8 and 20 of fermentation were in all cases, except Sp PEF, above the perception threshold, which can cause fusel aromas and even irritants [39]. The predominant alcohol, 2-methyl 1-butanol, in no case exceeded the perception threshold; however, isobutanol in Td and Mp yeasts with PEF on day 20 was within the perceptible taste threshold of $75 \mathrm{mg} / \mathrm{L}$ [40]. As in previous articles, the 1-propanol production was always higher at the end of fermentations in the inoculations with Lt PEF compared to the other yeasts and the other untreated wine on days 8 and 20, being more accentuated the higher the amount of lactic acid produced. A possible cause could be the small-scale fermentations; it was reported that it seems that at a large scale, this compound decreases [14,41]. To continue, carbonyl compounds, with buttery and caramel aromas, have a low perception threshold; in the case of diacetyl, no fermentation reached this threshold, and though it could be detected in acetoin, this was very dependent on the grape variety [42,43]. Finally, esters are closely related to readily assimilable nitrogen (YAN) [44] and to fermentation time. In no case did ethyl acetate exceed $60 \mathrm{mg} / \mathrm{L}$ to produce undesirable varnish aromas [41]. Ethyl lactate was much 
higher on day 20 than the rest in the Lt PEF. This is a direct consequence of the strong lactic acid production by most Lt strains and coincides with recent research developed on the influence of Lt on the fermentative aroma of wine [34,45], although it remains far from the perception threshold [46]. Both isobutyl acetate and isoamyl acetate were slightly above the perception threshold, with tropical fruit aromas in all cases [47], and 2-phenylethyl acetate was higher in Hv PEF. This is a specific characteristic of this yeast and it has been seen that with better implantation of the yeast, this aromatic ester with rose odour is higher [48,49]. As in previous studies, Td PEF produced 3-ethoxy-1-propanol, which was lost during fermentation but somewhat conserved on day 20 [17].

Research shows that the application of low-energy PEF $(<10 \mathrm{~kJ} / \mathrm{Kg})$ can accelerate the extraction of polyphenols $[3,50]$; however, as there were no skins in the second PEF treatment, the small difference in anthocyanins seen between the PEF-treated wine and the untreated wine are due to the characteristics of each yeast. The most significant result was in vitisin A with Sp PEF, which is a specific property of this yeast, and at the same time, this yeast was one of those with the lowest amount of total anthocyanins [51]. It was also seen that $\mathrm{Sc}$ in both cases produced more vitisin B than the rest due to a higher amount of acetaldehyde at the end of fermentation (a precursor of vitisin B) [52]. Vinylphenolic pyranoanthocyanins (VPA) are formed due to the enzymatic activity hydroxycinnamate decarboxylase (HCDC) of the Sc species and it has also been seen that certain strains of Sp can produce it [53], but in our case, both Lt control, Sp control and both Mp were due to better and faster implantation of wild yeasts. Regarding wine colour, the lower colour intensity in the grapes fermented with Sc PEF is potentially associated with the formation of insoluble polymeric pigments [54]. The second round of PEF was performed on must without skins, resulting in a lower extraction of colour and pigments.

Finally, in the overall wine sensory analysis, the different yeasts and treatments were able to generate very different and complex wines with almost no defects compared to the pure culture of $S$. cerevisiae. Tasters were generally better able to notice the characteristics of each yeast in the musts treated with PEF due to better implantation of the selected microbiota. Greater colour intensity was noted in the wines without PEF, which is consistent with the data provided by the spectrophotometer. The hue in the wine with Lt PEF was one of the lowest due to the protection exerted by the high acidity produced by the yeast in that wine [14]. As for the fruit that the tasters found in the wines, they agreed that they found more in the wines with Lt and Sp PEF since they were among those with the most esters. In general, no differences were detected between the treated and untreated wines [55], except for the Sp yeast; the changes were due to the better or worse implantation of the selected yeast, although they were not very noticeable either, which means that the PEF treatment did not sufficiently decrease the indigenous population for optimal or full expression of the metabolites specific to each yeast.

\section{Conclusions}

The use of PEF improves polyphenol extraction with a few hours of maceration and decreases wild microbiota to improve the implantation of selected non-Saccharomyces yeasts, which improves the qualities of each yeast by having a lower competitiveness between yeasts, such as wine acidity, production of fermentative volatiles including esters, and formation of derived anthocyanins, particularly vitisin A. The combined use of emerging nonthermal technologies, such as PEF and non-Saccharomyces yeast fermentation, improves the organoleptic profile of wines and reduces the use of sulphites.

Supplementary Materials: The following are available online at https:/ / www.mdpi.com/article/10 .3390 / foods10071472/s1, Table S1: Results of the sensory analysis of the wines. Values are means $\pm \mathrm{sd}(\mathrm{n}=3)$. Values with the same letter or without * in the same column are not significantly different $(p<0.05)$. 


\begin{abstract}
Author Contributions: C.V. and C.D. experimental work, C.V., I.L. and A.M.; literature review, writing, and editing; A.M. and C.V.; image design; J.R., I.Á. and C.D.; critical reading. A.M. and J.R. conceptualisation and experimental design. All authors have read and agreed to the published version of the manuscript.

Funding: Ministerio de Ciencia, Innovación y Universidades project: RTI2018-096626-B-I00 and European Regional Development Fund (ERDF), through the National Smart Growth Operational Programme FEDER INTERCONECTA EXP-00111498/ITC-20181125, project: FRESHWINES.
\end{abstract}

Conflicts of Interest: The authors declare that there are no conflict of interest.

\title{
References
}

1. Kotnik, T.; Rems, L.; Tarek, M.; Miklavčič, D. Membrane Electroporation and Electropermeabilization: Mechanisms and Models. Annu. Rev. Biophys. 2019, 48, 63-91. [CrossRef]

2. Barba, F.J.; Parniakov, O.; Pereira, S.A.; Wiktor, A.; Grimi, N.; Boussetta, N.; Saraiva, J.A.; Raso, J.; Martin-Belloso, O.; WitrowaRajchert, D.; et al. Current applications and new opportunities for the use of pulsed electric fields in food science and industry. Food Res. Int. 2015, 77, 773-798. [CrossRef]

3. López-Giral, N.; González-Arenzana, L.; González-Ferrero, C.; López, R.; Santamaría, P.; Alfaro, I.L.; Garde-Cerdán, T. Pulsed electric field treatment to improve the phenolic compound extraction from Graciano, Tempranillo and Grenache grape varieties during two vintages. Innov. Food Sci. Emerg. Technol. 2015, 28, 31-39. [CrossRef]

4. Leong, S.Y.; Burritt, D.J.; Oey, I. Evaluation of the anthocyanin release and health-promoting properties of Pinot Noir grape juices after pulsed electric fields. Food Chem. 2016, 196, 833-841. [CrossRef]

5. Maza, M.A.; Martínez, J.M.; Hernández-Orte, P.; Cebrián, G.; Sánchez-Gimeno, A.C.; Álvarez, I.; Raso, J. Influence of pulsed electric fields on aroma and polyphenolic compounds of Garnacha wine. Food Bioprod. Process. 2019, 116, 249-257. [CrossRef]

6. Ayuda, M.-I.; Ferrer-Pérez, H.; Pinilla, V. Explaining World Wine Exports in the First Wave of Globalization, 1848-1938. J. Wine Econ. 2020, 15, 263-283. Available online: https://www.cambridge.org/core/product/identifier/S1931436120000048/type/ journal_article (accessed on 2 June 2020). [CrossRef]

7. Cocolin, L.; Rantsiou, K.; Iacumin, L.; Zironi, R.; Comi, G. Molecular Detection and Identification of Brettanomyces/Dekkera bruxellensis and Brettanomyces/Dekkera anomalus in Spoiled Wines. Appl. Environ. Microbiol. 2004, 70, 1347-1355. Available online: https: / / aem.asm.org/content/70/3/1347 (accessed on 8 March 2004). [CrossRef]

8. Stivala, M.G.; Villecco, M.B.; Enriz, D.; Aredes Fernández, P. Effect of Phenolic Compounds on Viability of Wine Spoilage Lactic Acid Bacteria. A Structure-Activity Relationship Study. Am. J. Enol. Vitic. 2017, 68, 228-233. [CrossRef]

9. Garaguso, I.; Nardini, M. Polyphenols content, phenolics profile and antioxidant activity of organic red wines produced without sulfur dioxide/sulfites addition in comparison to conventional red wines. Food Chem. 2015, 179, 336-342. [CrossRef]

10. Saldaña, G.; Puértolas, E.; López, N.; García, D.; Álvarez, I.; Raso, J. Comparing the PEF resistance and occurrence of sublethal injury on different strains of Escherichia coli, Salmonella Typhimurium, Listeria monocytogenes and Staphylococcus aureus in media of pH 4 and 7. Innov. Food Sci. Emerg. Technol. 2009, 10, 160-165. [CrossRef]

11. Ricci, A.; Parpinello, G.P.; Versari, A. Recent Advances and Applications of Pulsed Electric Fields (PEF) to Improve Polyphenol Extraction and Color Release during Red Winemaking. Beverages 2018, 4, 18. Available online: http://www.mdpi.com/2306-571 0/4/1/18 (accessed on 1 March 2018). [CrossRef]

12. Delsart, C.; Grimi, N.; Boussetta, N.; Sertier, C.M.; Ghidossi, R.; Peuchot, M.M.; Vorobiev, E. Comparison of the effect of pulsed electric field or high voltage electrical discharge for the control of sweet white must fermentation process with the conventional addition of sulfur dioxide. Food Res. Int. 2015, 77, 718-724. [CrossRef]

13. Morata, A.; Bañuelos, M.A.; Loira, I.; Raso, J.; Álvarez, I.; Garcíadeblas, B.; González, C.; Lepe, J.A.S. Grape Must Processed by Pulsed Electric Fields: Effect on the Inoculation and Development of Non-Saccharomyces Yeasts. Food Bioprocess Technol. 2020, 13, 1087-1094. [CrossRef]

14. Vaquero, C.; Loira, I.; Bañuelos, M.A.; Heras, J.M.; Cuerda, R.; Morata, A. Industrial performance of several Lachancea thermotolerans strains for $\mathrm{pH}$ control in white wines from warm areas. Microorganisms 2020, 8, 830. Available online: https: //www.mdpi.com/2076-2607/8/6/830 (accessed on 1 June 2020). [CrossRef] [PubMed]

15. Muñoz-Redondo, J.M.; Puertas, B.; Cantos-Villar, E.; Jiménez-Hierro, M.J.; Carbú, M.; Garrido, C.; Ruiz-Moreno, M.J.; MorenoRojas, J.M. Impact of Sequential Inoculation with the Non-Saccharomyces T. delbrueckii and M. pulcherrima Combined with Saccharomyces cerevisiae Strains on Chemicals and Sensory Profile of Rosé Wines. J. Agric. Food Chem. 2021, 69, 1598-1609. [CrossRef] [PubMed]

16. Drumonde-Neves, J.; Fernandes, T.; Lima, T.; Pais, C.; Franco-Duarte, R. Learning from 80 years of studies: A comprehensive catalogue of non-Saccharomyces yeasts associated with viticulture and winemaking. FEMS Yeast Res. 2021, 21, foab017. [CrossRef]

17. Vaquero, C.; Loira, I.; Heras, J.M.; Carrau, F.; González, C.; Morata, A. Biocompatibility in Ternary Fermentations With Lachancea thermotolerans, Other Non-Saccharomyces and Saccharomyces cerevisiae to Control pH and Improve the Sensory Profile of Wines From Warm Areas. Front. Microbiol. 2021, 12, 656262. [CrossRef]

18. Abalos, D.; Vejarano, R.; Morata, A.; González, C.; Suárez-Lepe, J.A. The use of furfural as a metabolic inhibitor for reducing the alcohol content of model wines. Eur. Food Res. Technol. 2011, 232, 663-669. [CrossRef] 
19. Loira, I.; Vejarano, R.; Morata, A.; Ricardo-Da-Silva, J.M.; Laureano, O.; Gonzalez, M.; Suárez-Lepe, J. Effect of Saccharomyces strains on the quality of red wines aged on lees. Food Chem. 2013, 139, 1044-1051. [CrossRef]

20. Bañuelos, M.A.; Loira, I.; Escott, C.; Del Fresno, J.M.; Morata, A.; Sanz, P.D.; Otero, L.; Suárez-Lepe, J.A. Grape processing by high hydrostatic pressure: Effect on use of non-Saccharomyces in must fermentation. Food Bioprocess Technol. 2016, 9, 1769-1778. [CrossRef]

21. Maza, M.A.; Pereira, C.; Martínez, J.M.; Camargo, A.; Álvarez, I.; Raso, J. PEF treatments of high specific energy permit the reduction of maceration time during vinification of Caladoc and Grenache grapes. Innov. Food Sci. Emerg. Technol. 2020, 63, 102375. [CrossRef]

22. Ozturk, B.; Anli, E. Pulsed electric fields (PEF) applications on wine production: A review. BIO Web Conf. 2017, 9, 02008. [CrossRef]

23. Puértolas, E.; López, N.; Condón, S.; Álvarez, I.; Raso, J. Potential applications of PEF to improve red wine quality. Trends Food Sci. Technol. 2010, 21, 247-255. Available online: https:/ /linkinghub.elsevier.com/retrieve/pii/S0924224410000609 (accessed on 16 February 2010). [CrossRef]

24. Kotnik, T.; Kramar, P.; Pucihar, G.; Miklavcic, D.; Tarek, M. Cell Membrane Electroporation—Part 1: The Phenomenon. IEEE Electr. Insul. Mag. 2012, 28, 14-23. Available online: http://ieeexplore.ieee.org/document/6268438/ (accessed on 16 August 2012). [CrossRef]

25. Garde-Cerdán, T.; Marsellés-Fontanet, A.R.; Arias-Gil, M.; Ancín-Azpilicueta, C.; Martín-Belloso, O. Influence of SO2 on the evolution of volatile compounds through alcoholic fermentation of must stabilized by pulsed electric fields. Eur. Food Res. Technol. 2007, 227, 401-408. [CrossRef]

26. Emanuel, E.; Dubrovin, I.; Hanya, E.; Pinhasi, G.A.; Pogreb, R.; Cahan, R. Eradication of Saccharomyces cerevisiae by Pulsed Electric Field Treatments. Microorganisms 2020, 8, 1684. Available online: https:/ /www.mdpi.com/2076-2607/8/11/1684 (accessed on 29 October 2020). [CrossRef] [PubMed]

27. Medina, K.; Boido, E.; Dellacassa, E.; Carrau, F. Growth of non-Saccharomyces yeasts affects nutrient availability for Saccharomyces cerevisiae during wine fermentation. Int. J. Food Microbiol. 2012, 157, 245-250. [CrossRef]

28. Martin, V.; Valera, M.; Medina, K.; Boido, E.; Carrau, F. Oenological Impact of the Hanseniaspora/Kloeckera Yeast Genus on Wines-A Review. Fermentation 2018, 4, 76. Available online: http://www.mdpi.com/2311-5637/4/3/76 (accessed on 10 September 2018). [CrossRef]

29. Morata, A.; Loira, I.; Tesfaye, W.; Bañuelos, M.; González, C.; Suárez Lepe, J. Lachancea thermotolerans Applications in Wine Technology. Fermentation 2018, 4, 53. Available online: http:/ / www.mdpi.com/2311-5637/4/3/53 (accessed on 11 July 2018). [CrossRef]

30. Canonico, L.; Agarbati, A.; Comitini, F.; Ciani, M. Torulaspora delbrueckii in the brewing process: A new approach to enhance bioflavour and to reduce ethanol content. Food Microbiol. 2016, 56, 45-51. [CrossRef]

31. Canonico, L.; Comitini, F.; Ciani, M. Torulaspora delbrueckii for secondary fermentation in sparkling wine production. Food Microbiol. 2018, 74, 100-106. [CrossRef]

32. Nardi, T.; Panero, L.; Petrozziello, M.; Guaita, M.; Tsolakis, C.; Cassino, C.; Vagnoli, P.; Bosso, A. Managing wine quality using Torulaspora delbrueckii and Oenococcus oeni starters in mixed fermentations of a red Barbera wine. Eur. Food Res. Technol. 2018, 245, 293-307. [CrossRef]

33. Binati, R.L.; Innocente, G.; Gatto, V.; Celebrin, A.; Polo, M.; Felis, G.E.; Torriani, S. Exploring the diversity of a collection of native non-Saccharomyces yeasts to develop co-starter cultures for winemaking. Food Res. Int. 2019, 122, 432-442. [CrossRef]

34. Morata, A.; Bañuelos, M.A.; Vaquero, C.; Loira, I.; Cuerda, R.; Palomero, F.; González, C.; Suárez-Lepe, J.A.; Wang, J.; Han, S.; et al. Lachancea thermotolerans as a tool to improve $\mathrm{pH}$ in red wines from warm regions. Eur. Food Res. Technol. 2019, 245, 885-894. [CrossRef]

35. Loira, I.; Morata, A.; Palomero, F.; González, C.; Suárez-Lepe, J. Schizosaccharomyces pombe: A Promising Biotechnology for Modulating Wine Composition. Fermentation 2018, 4, 70. Available online: http:/ / www.mdpi.com/2311-5637/4/3/70 (accessed on 23 August 2018). [CrossRef]

36. Jolly, N.P.; Varela, C.; Pretorius, I.S. Not your ordinary yeast: Non- Saccharomyces yeasts in wine production uncovered. FEMS Yeast Res. 2014, 14, 215-237. [CrossRef]

37. Esteve-Zarzoso, B.; Manzanares, P.; Ramón, D.; Querol, A. The role of non-Saccharomyces yeasts in industrial winemaking. Int. Microbiol. 1998, 1, 143-148. Available online: http:/ / www.ncbi.nlm.nih.gov/pubmed/10943352 (accessed on 1 June 1998).

38. Petitgonnet, C.; Klein, G.L.; Roullier-Gall, C.; Schmitt-Kopplin, P.; Quintanilla-Casas, B.; Vichi, S.; Julien-David, D.; Alexandre, $\mathrm{H}$. Influence of cell-cell contact between L. thermotolerans and S. cerevisiae on yeast interactions and the exo-metabolome. Food Microbiol. 2019, 83, 122-133. [CrossRef] [PubMed]

39. Rapp, A.; Versini, G. Influence of nitrogen compounds in grapes on aroma compounds of wines. Dev. Food Sci. 1995, 37, 1659-1694. Available online: https:/ /linkinghub.elsevier.com/retrieve/pii/S0167450106802578 (accessed on 2 September 2007).

40. Balikci, E.K.; Tanguler, H.; Jolly, N.P.; Erten, H. Influence of Lachancea thermotolerans on cv. Emir wine fermentation. Yeast 2016, 33, 313-321. [CrossRef] [PubMed]

41. Gobbi, M.; Comitini, F.; Domizio, P.; Romani, C.; Lencioni, L.; Mannazzu, I.; Ciani, M. Lachancea thermotolerans and Saccharomyces cerevisiae in simultaneous and sequential co-fermentation: A strategy to enhance acidity and improve the overall quality of wine. Food Microbiol. 2013, 33, 271-281. [CrossRef] 
42. Bartowsky, E.J.; Henschke, P.A. The 'buttery' attribute of wine-diacetyl—desirability, spoilage and beyond. Int. J. Food Microbiol. 2004, 96, 235-252. Available online: https:/ /linkinghub.elsevier.com/retrieve/pii/S0168160504002867 (accessed on 1 August 2004). [CrossRef] [PubMed]

43. Rogerson, F.S.S.; Castro, H.; Fortunato, N.; Azevedo, Z.; Macedo, A.; De Freitas, V.A.P. Chemicals with sweet aroma descriptors found in Portuguese wines from the Douro region: 2,6,6-Trimethylcyclohex-2-ene-1,4-dione and diacetyl. J. Agric. Food Chem. 2000, 49, 263-269. [CrossRef] [PubMed]

44. Carrau, F.M.; Medina, K.; Farina, L.; Boido, E.; Henschke, P.A.; Dellacassa, E. Production of fermentation aroma compounds by Saccharomyces cerevisiae wine yeasts: Effects of yeast assimilable nitrogen on two model strains. FEMS Yeast Res. 2008, 8, $1196-1207$. [CrossRef]

45. Sgouros, G.; Mallouchos, A.; Filippousi, M.; Banilas, G.; Nisiotou, A. Molecular Characterization and Enological Potential of A High Lactic Acid-Producing Lachancea thermotolerans Vineyard Strain. Foods 2020, 9, 595. Available online: https: //www.mdpi.com/2304-8158/9/5/595 (accessed on 7 May 2020). [CrossRef] [PubMed]

46. Peinado, R.A.; Moreno, J.; Medina, M.; Mauricio, J.C. Changes in volatile compounds and aromatic series in sherry wine with high gluconic acid levels subjected to aging by submerged flor yeast cultures. Biotechnol. Lett. 2004, 26, 757-762. [CrossRef]

47. Xu, Y.; Wang, D.; Li, H.G.; Hao, J.; Jiang, W.; Liu, Z.; Qin, Q. Flavor Contribution of Esters in Lager Beers and an Analysis of Their Flavor Thresholds. J. Am. Soc. Brew. Chem. 2017, 75, 201-206. [CrossRef]

48. Zhang, B.; Xu, D.; Duan, C.; Yan, G. Synergistic effect enhances 2-phenylethyl acetate production in the mixed fermentation of Hanseniaspora vineae and Saccharomyces cerevisiae. Process. Biochem. 2020, 90, 44-49. [CrossRef]

49. Viana, F.; Taillandier, P.; Valles, S.; Strehaiano, P.; Manzanares, P. 2-Phenylethyl Acetate Formation by Immobilized Cells of Hanseniaspora vineae in Sequential Mixed Fermentations. Am. J. Enol. Vitic. 2011, 62, 122-126. [CrossRef]

50. Donsì, F.; Ferrari, G.; Fruilo, M.; Pataro, G. Pulsed Electric Field-Assisted Vinification of Aglianico and Piedirosso Grapes. J. Agric. Food Chem. 2010, 58, 11606-11615. [CrossRef] [PubMed]

51. Loira, I.; Morata, A.; Comuzzo, P.; Callejo, M.J.; González, C.; Calderón, F.; Suárez-Lepe, J.A. Use of Schizosaccharomyces pombe and Torulaspora delbrueckii strains in mixed and sequential fermentations to improve red wine sensory quality. Food Res. Int. 2015, 76, 325-333. [CrossRef]

52. Morata, A.; Gómez-Cordovés, M.C.; Colomo, B.; Suárez, J.A. Pyruvic Acid and Acetaldehyde Production by Different Strains of Saccharomyces cerevisiae: Relationship with Vitisin A and B Formation in Red Wines. J. Agric. Food Chem. 2003, 51, 7402-7409. [CrossRef]

53. Morata, A.; Benito, S.; Loira, I.; Palomero, F.; González, M.C. Formation of pyranoanthocyanins by Schizosaccharomyces pombe during the fermentation of red must. Int. J. Food Microbiol. 2012, 159, 47-53. [CrossRef] [PubMed]

54. Figueiredo-González, M.; Cancho-Grande, B.; Simal-Gándara, J.; Teixeira, N.; Mateus, N.; De Freitas, V. The phenolic chemistry and spectrochemistry of red sweet wine-making and oak-aging. Food Chem. 2014, 152, 522-530. Available online: https: / /linkinghub.elsevier.com/retrieve/pii/S0308814613018736 (accessed on 9 December 2013). [CrossRef] [PubMed]

55. Yang, N.; Huang, K.; Lyu, C.; Wang, J. Pulsed electric field technology in the manufacturing processes of wine, beer, and rice wine: A review. Food Control 2016, 61, 28-38. [CrossRef] 